\title{
An Enantioselective Total Synthesis of (-)-Candelalide A, a Novel Blocker of the Voltage-Gated Potassium Channel Kv1.3 for an Immunosuppressive agent
}

- Supporting Information \#2 -

${ }^{1} \mathrm{H}-$ and ${ }^{13} \mathrm{C}-\mathrm{NMR}$ Spectra

Kazuhiro Watanabe, ${ }^{\dagger}$ Katsuhiko Iwasaki, ${ }^{+}$Toshiaki Abe, ${ }^{\ddagger}$ Munenori Inoue, ${ }^{\#}$ Kōichi Ohkubo, ${ }^{\dagger}$ Takeyuki Suzuki, ${ }^{\dagger}$ and Tadashi Katoh ${ }^{* \dagger}$

${ }^{\dagger}$ Tohoku Pharmaceutical University, 4-4-1 Komatsushima, Aoba-ku, Sendai 981-8558, Japan, ${ }^{\sharp}$ Department of Electronic Chemistry, Tokyo Institute of Technology, Nagatsuta, Yokohama 226-8502, Japan,

${ }^{\#}$ Sagami Chemical Research Center, 2743-1 Hayakawa, Ayase, Kanagawa 252-1193, Japan 

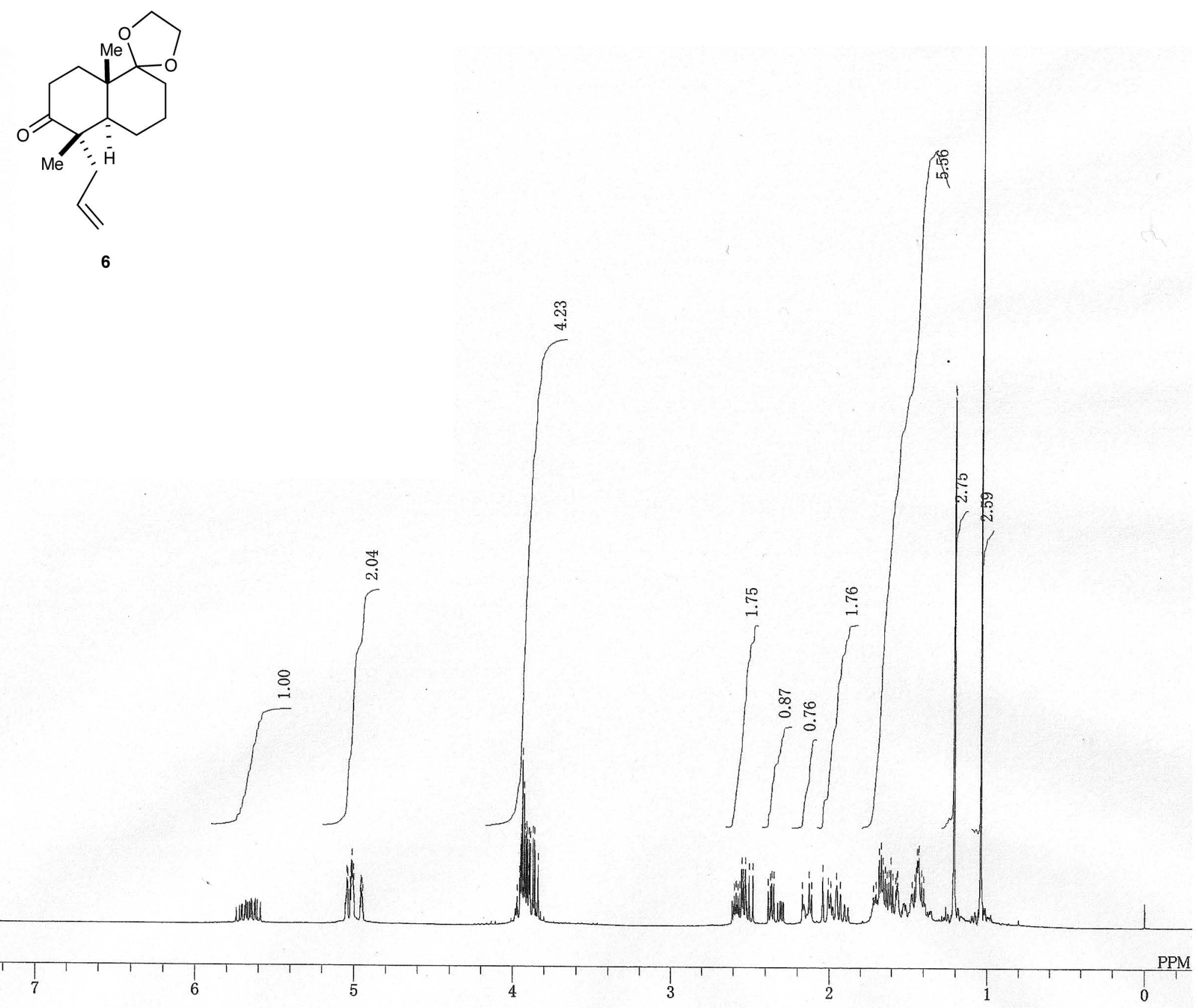


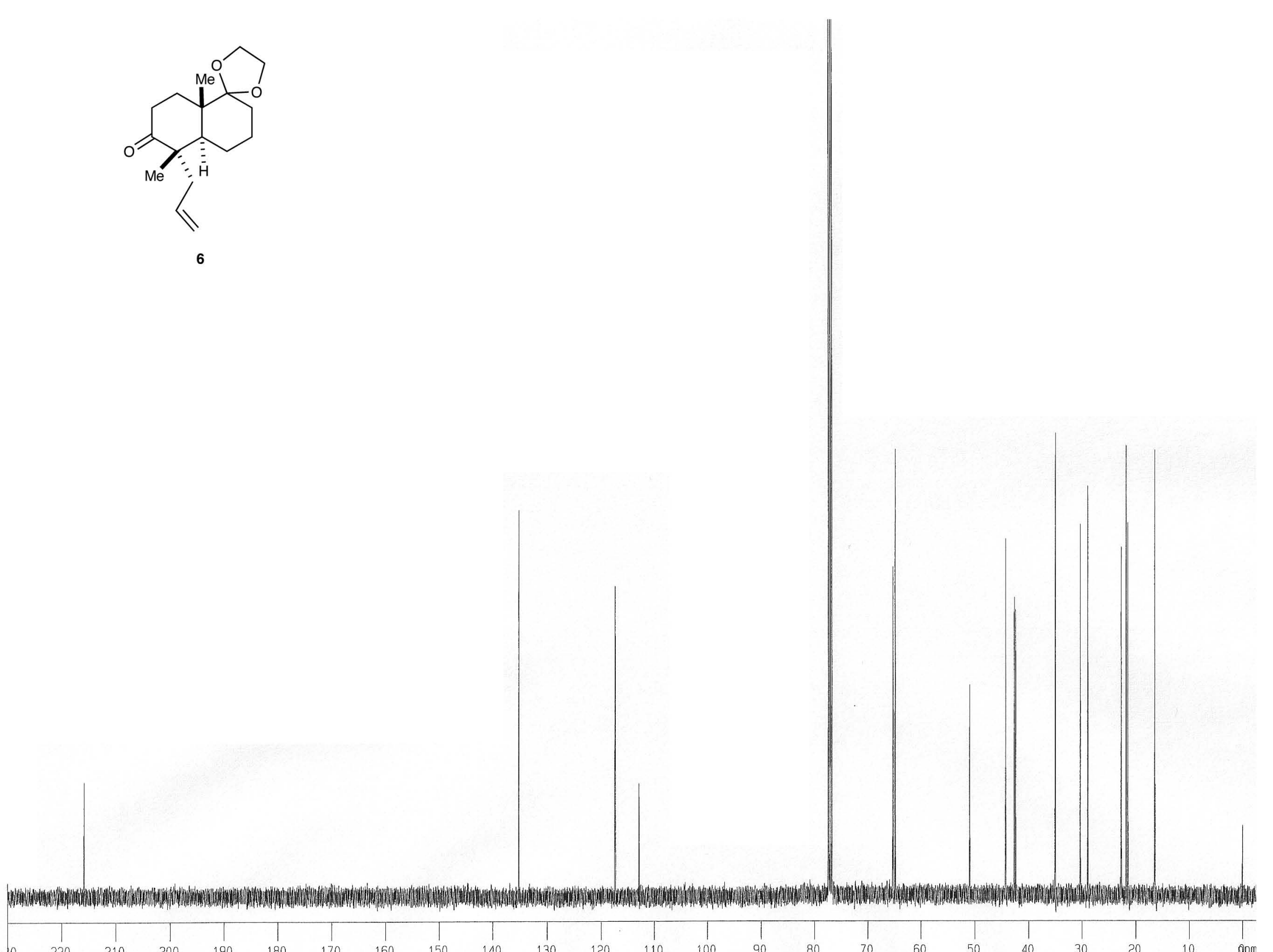




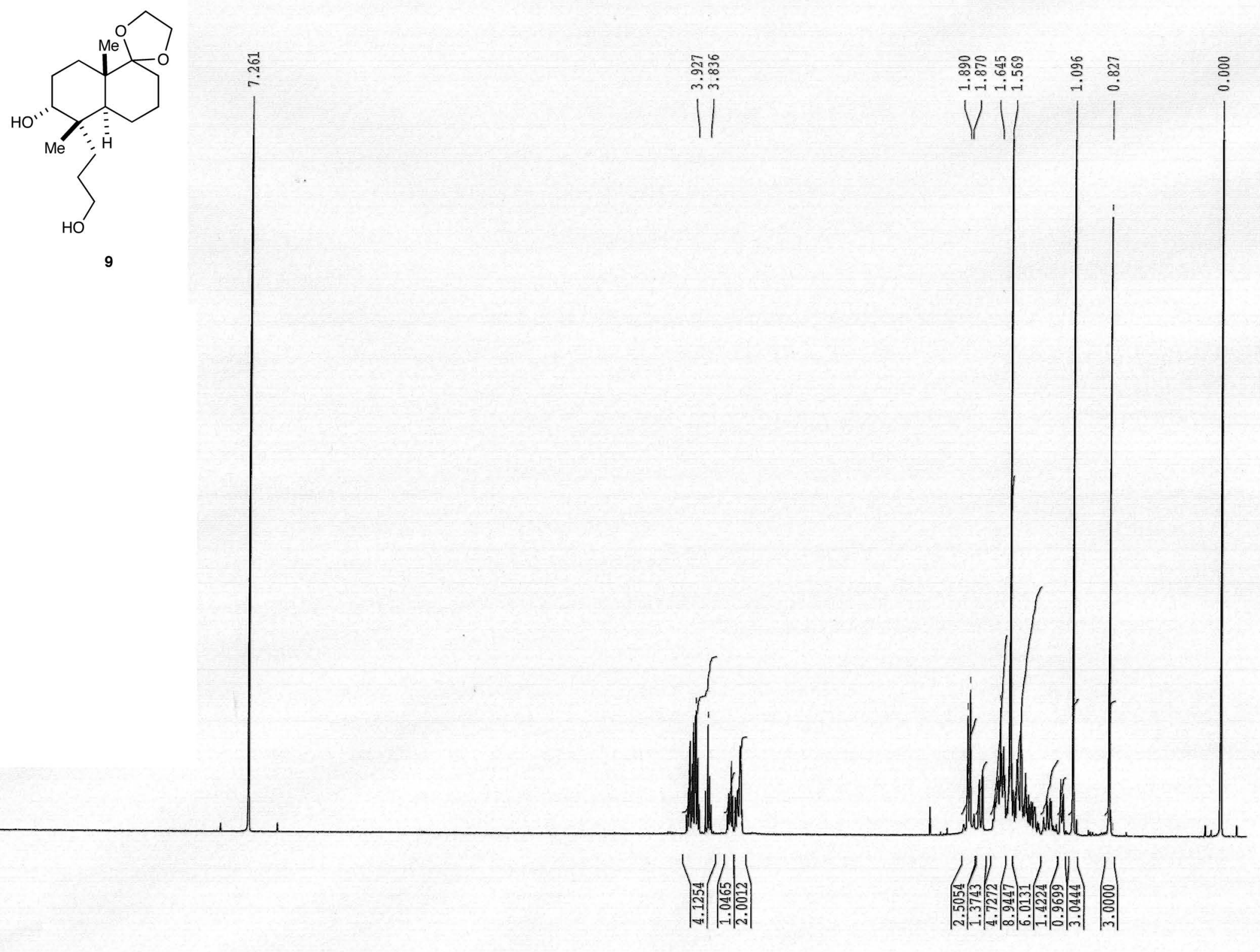



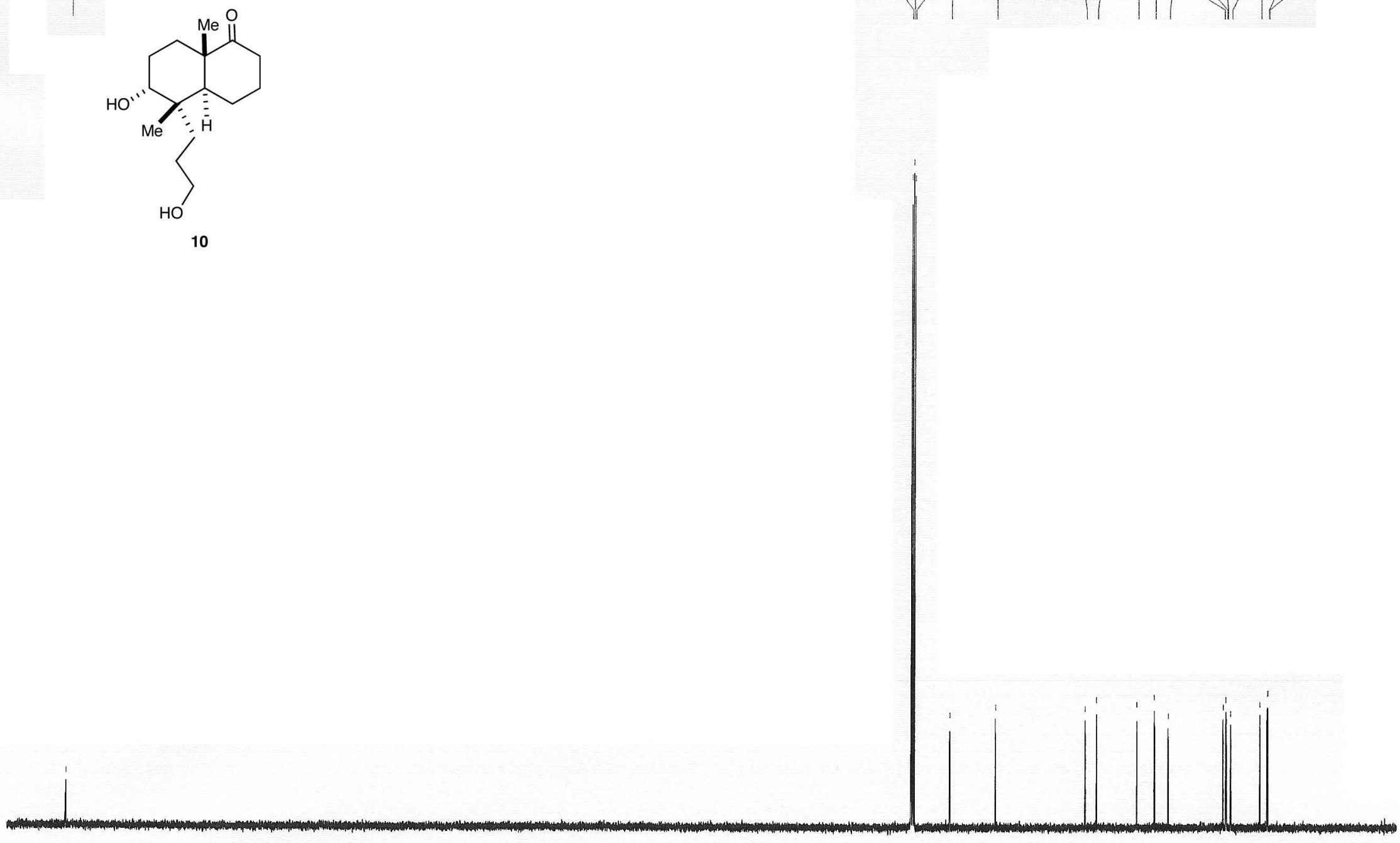


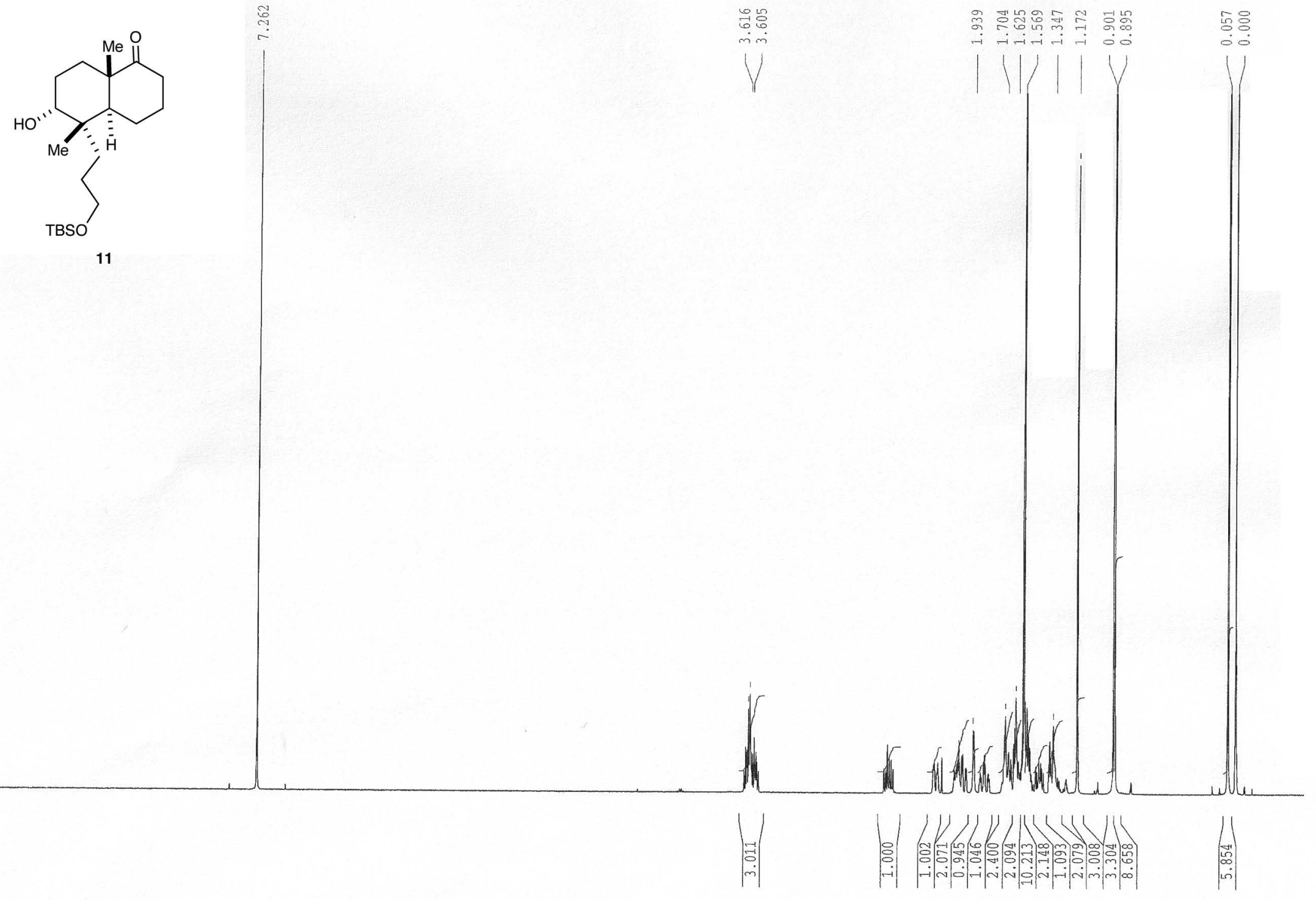




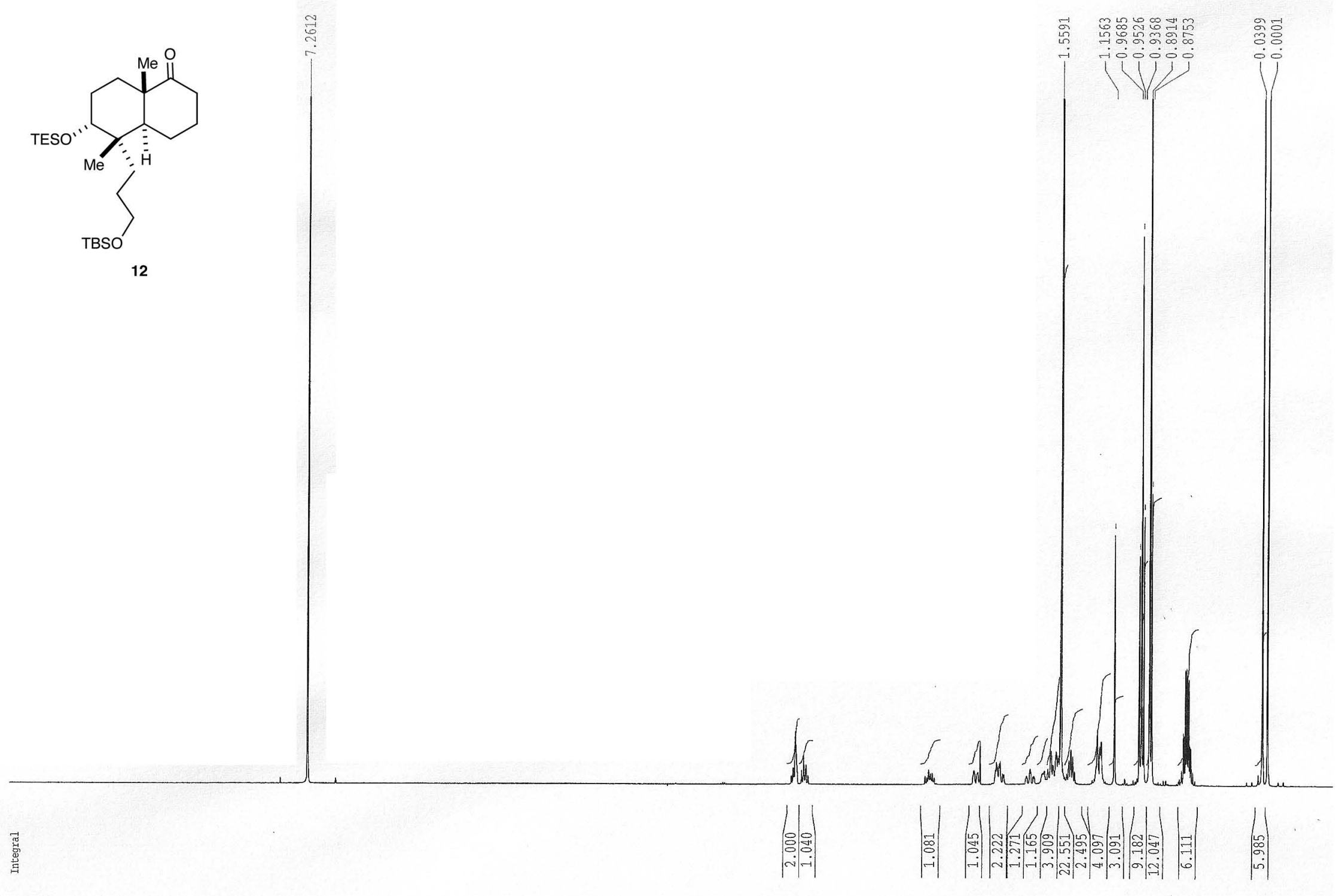



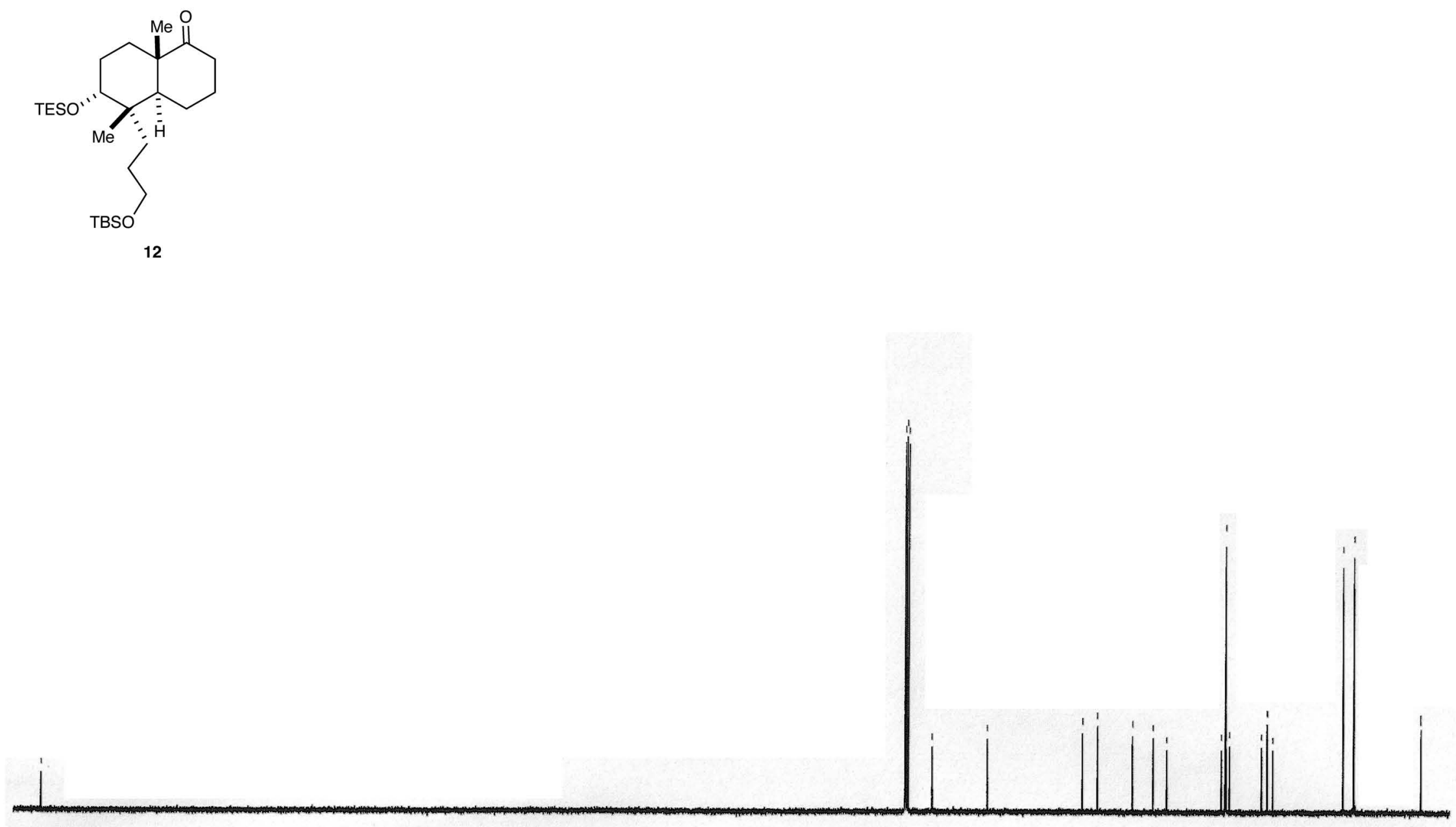

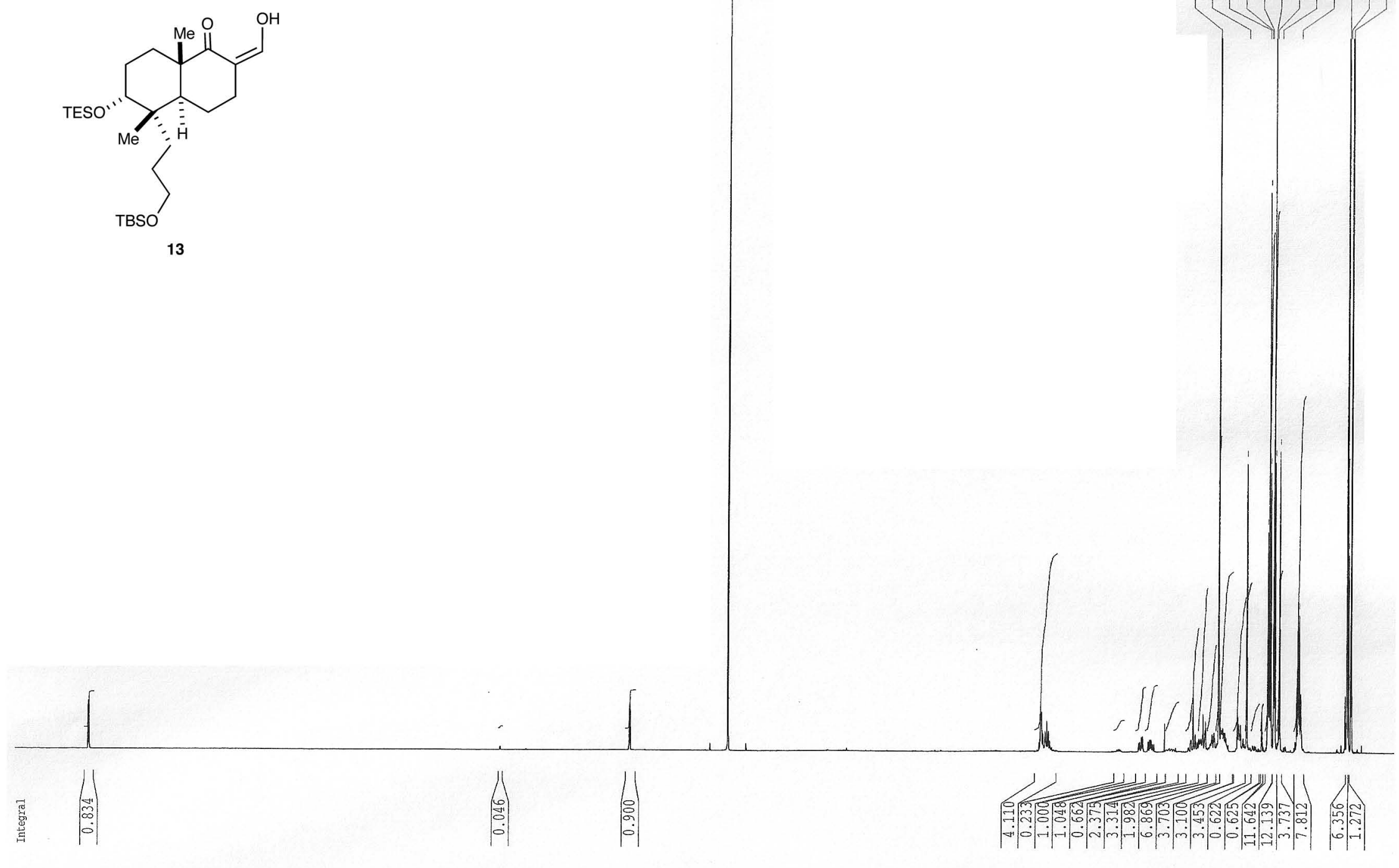


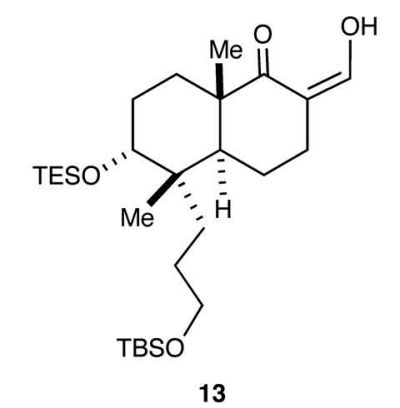




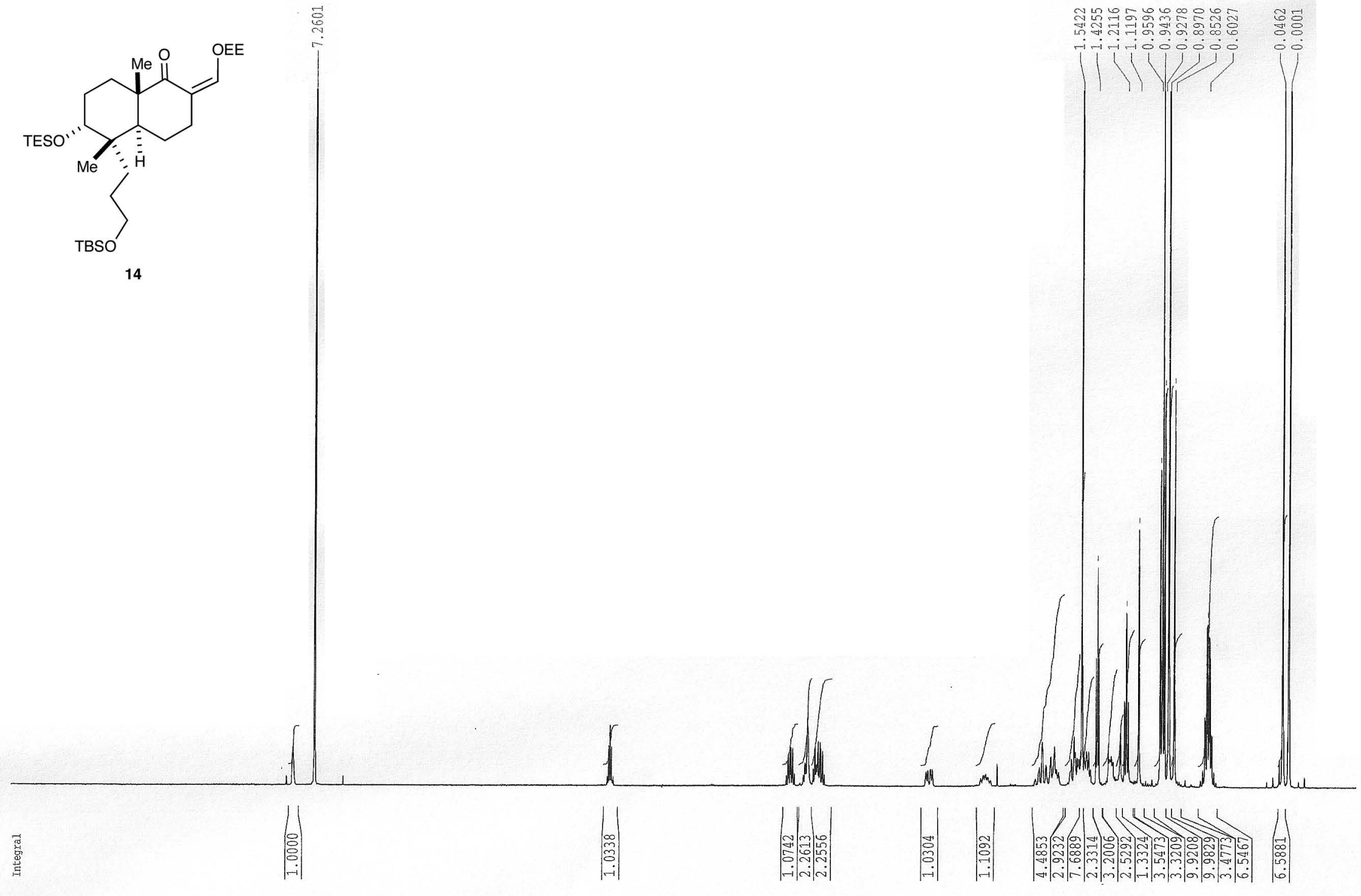



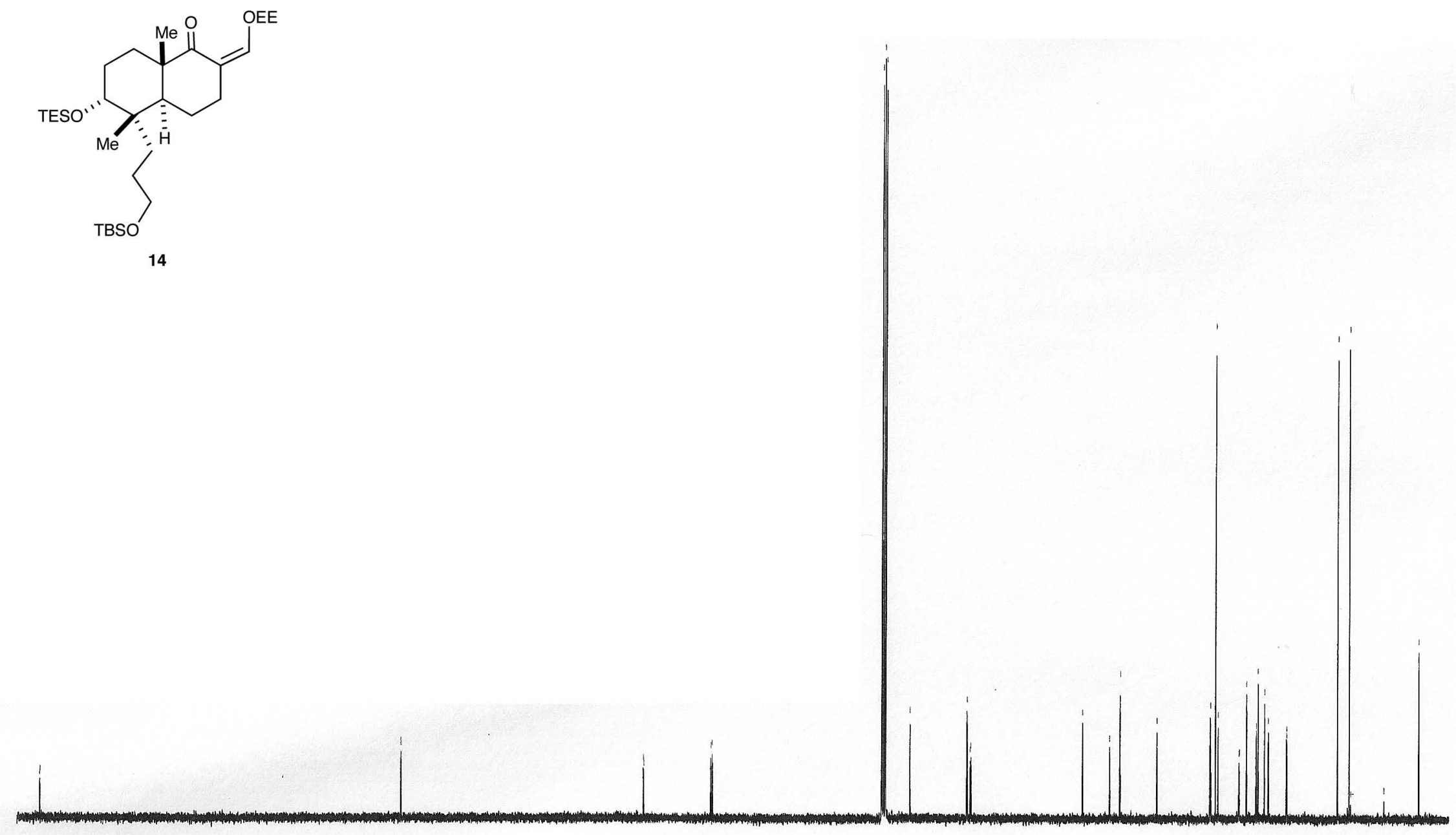


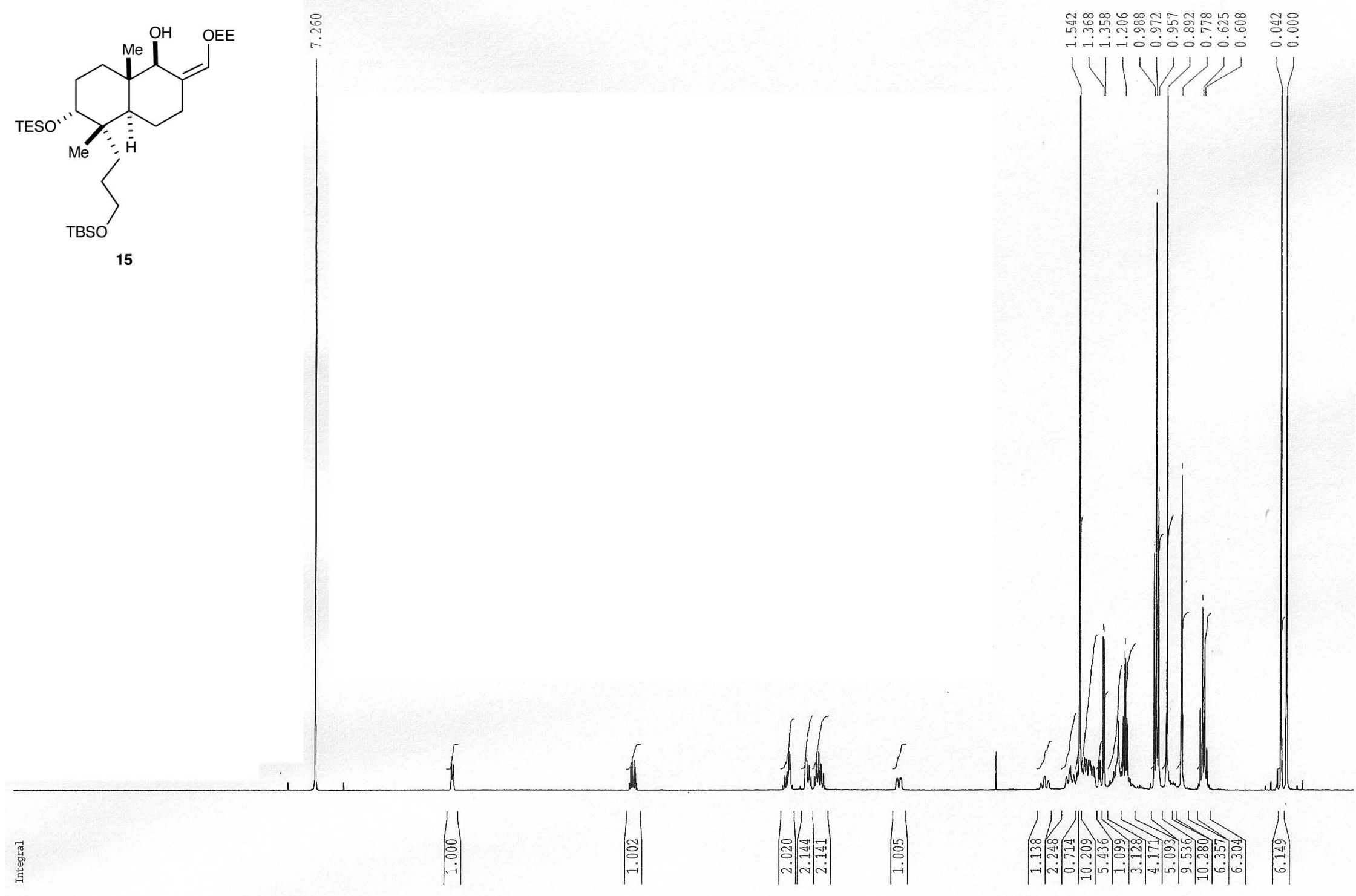




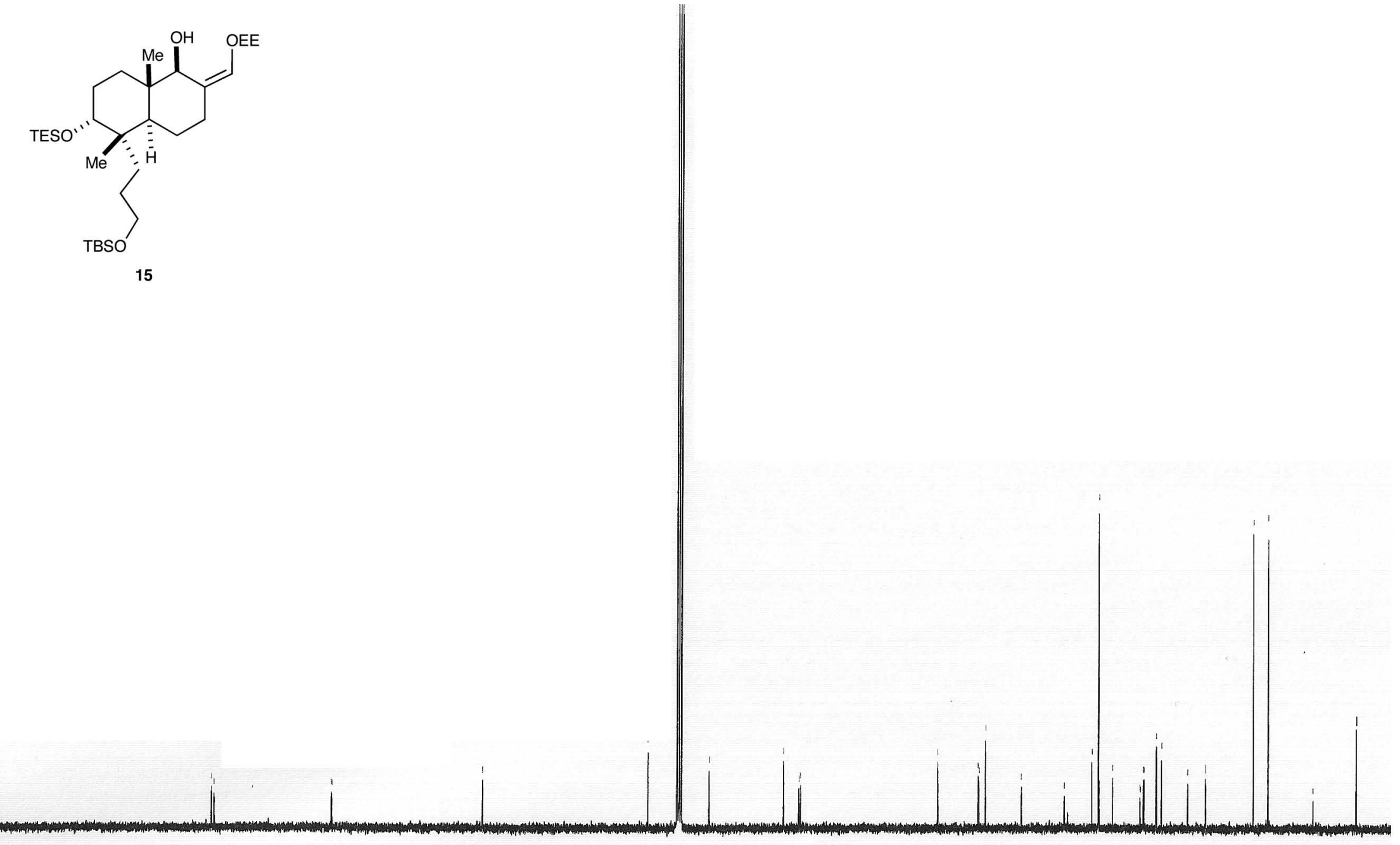




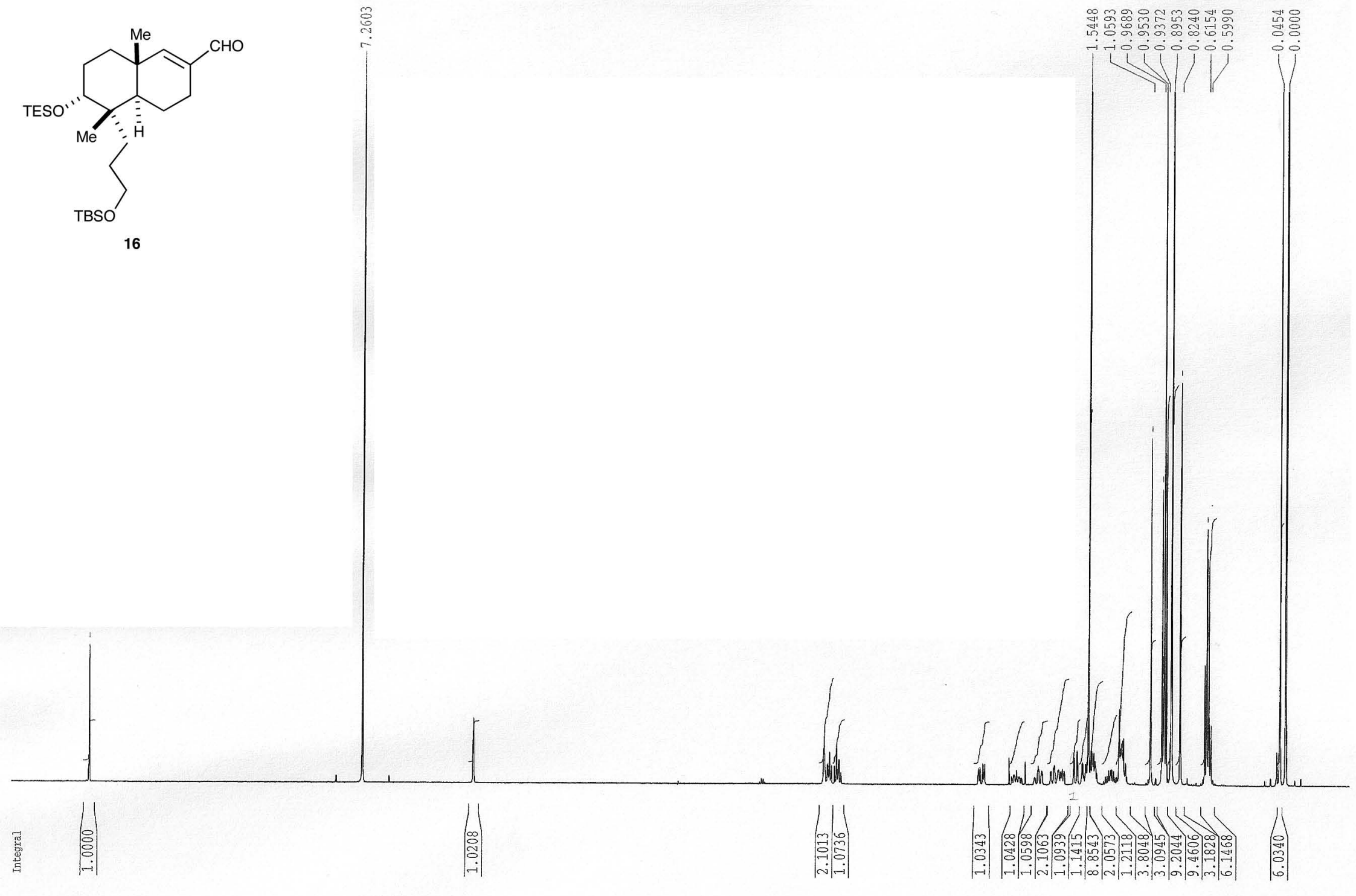



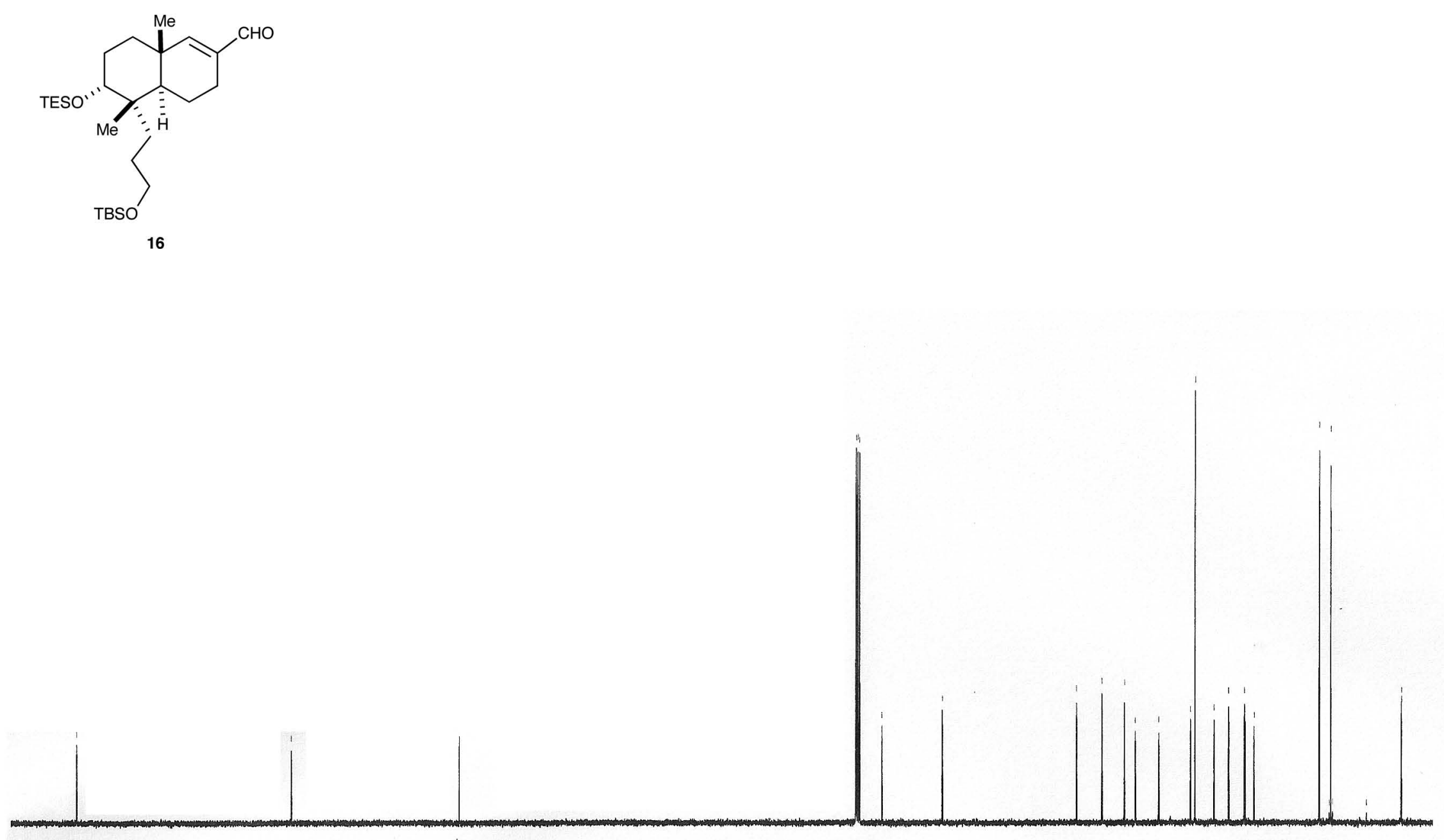


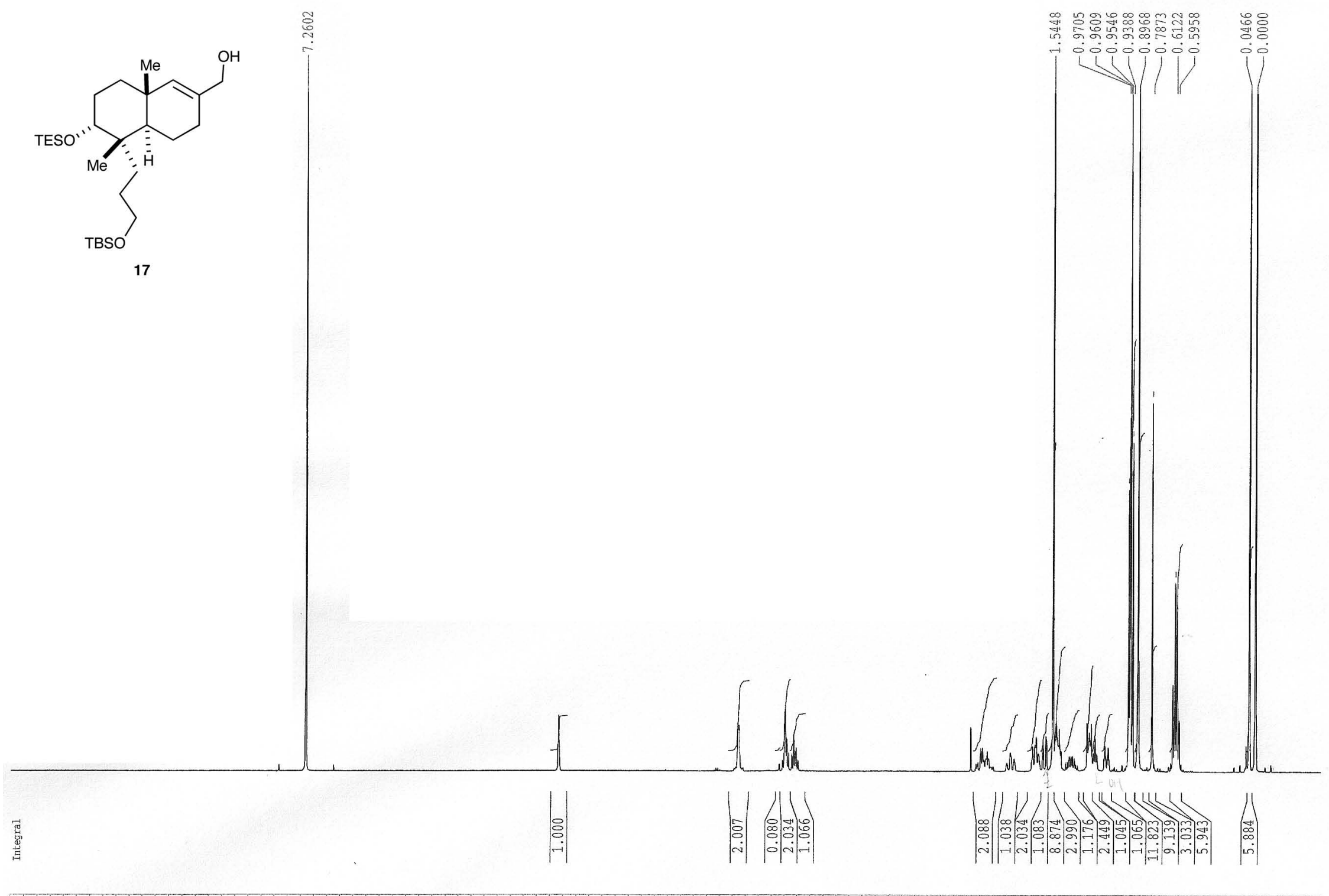




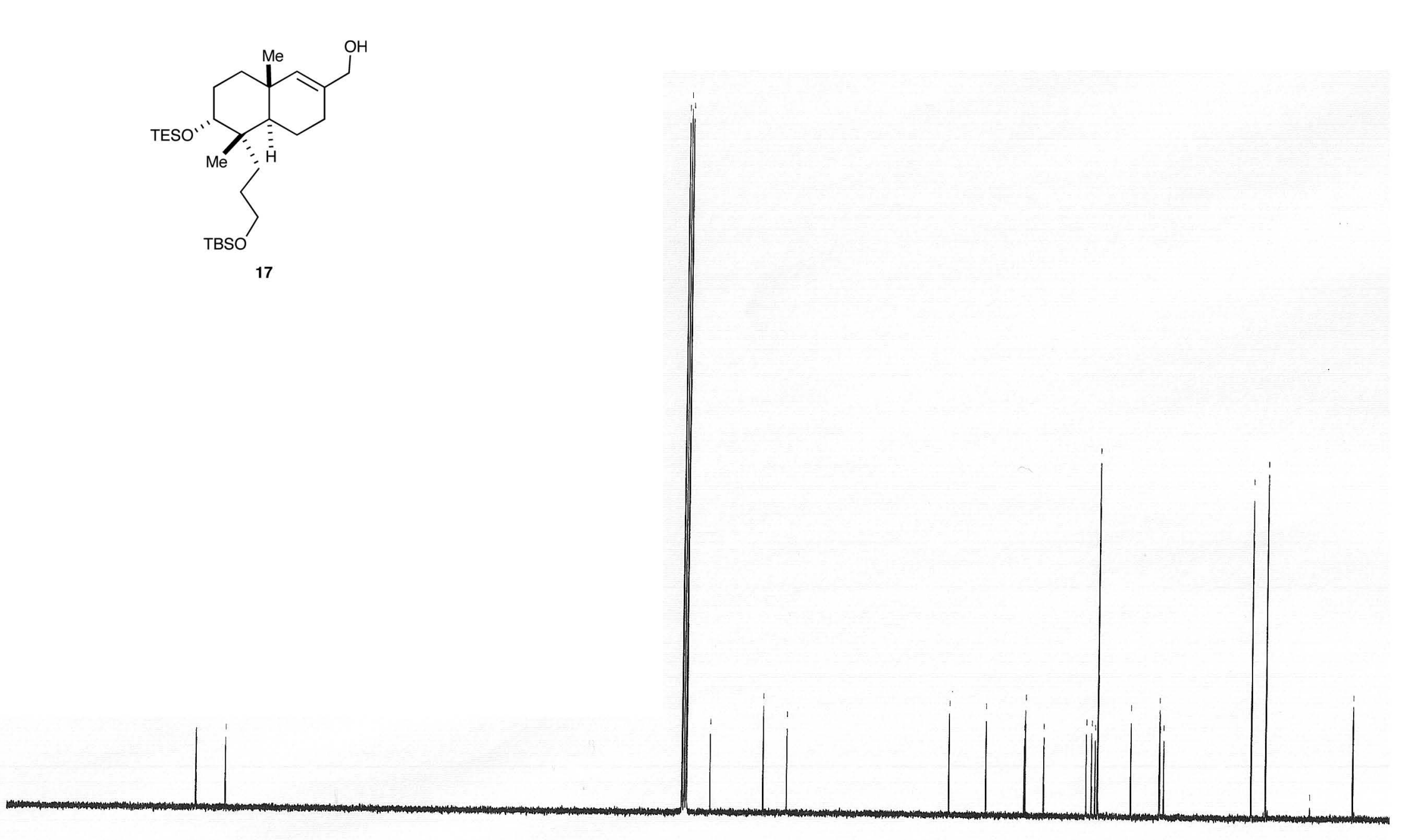




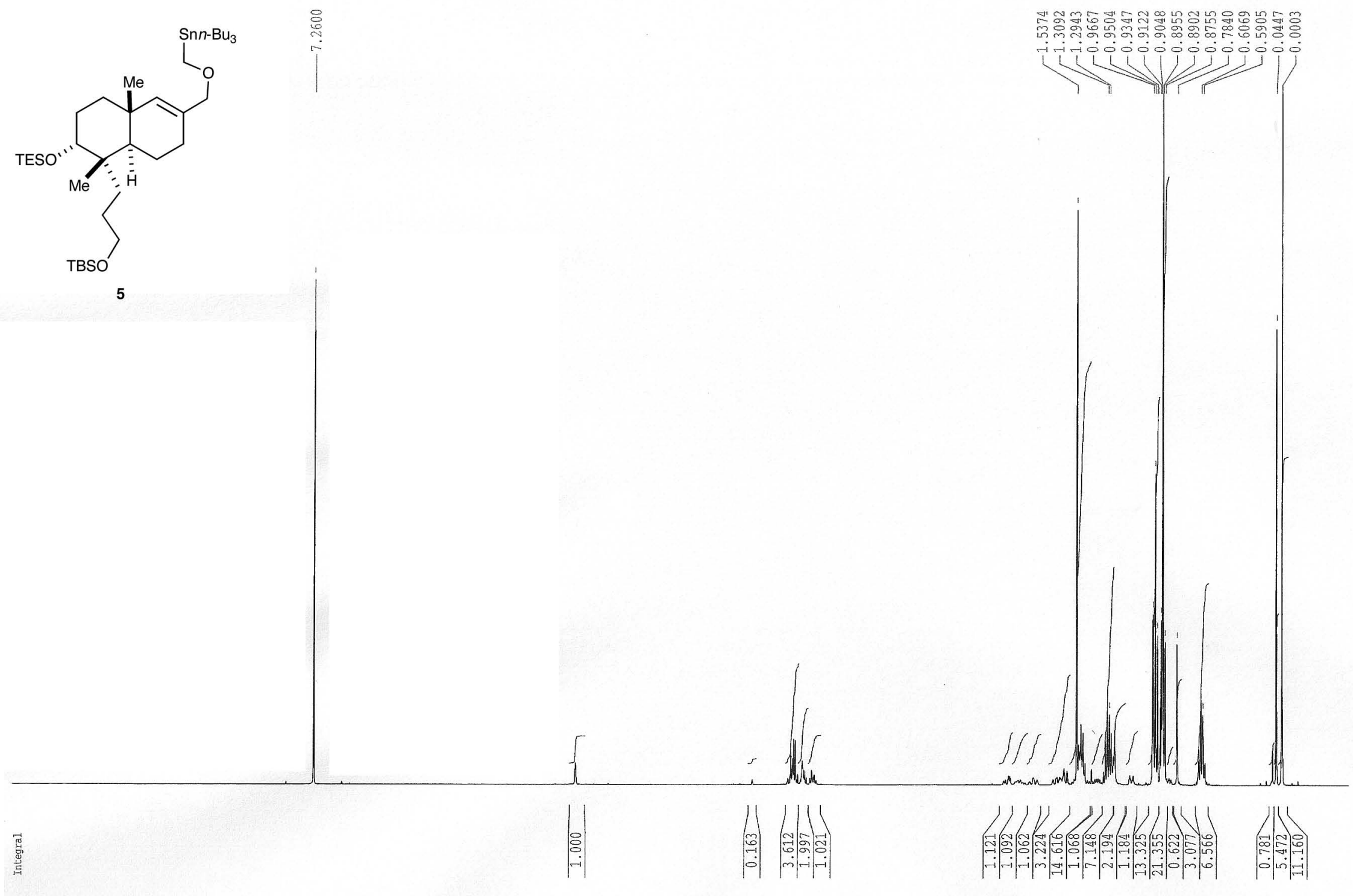




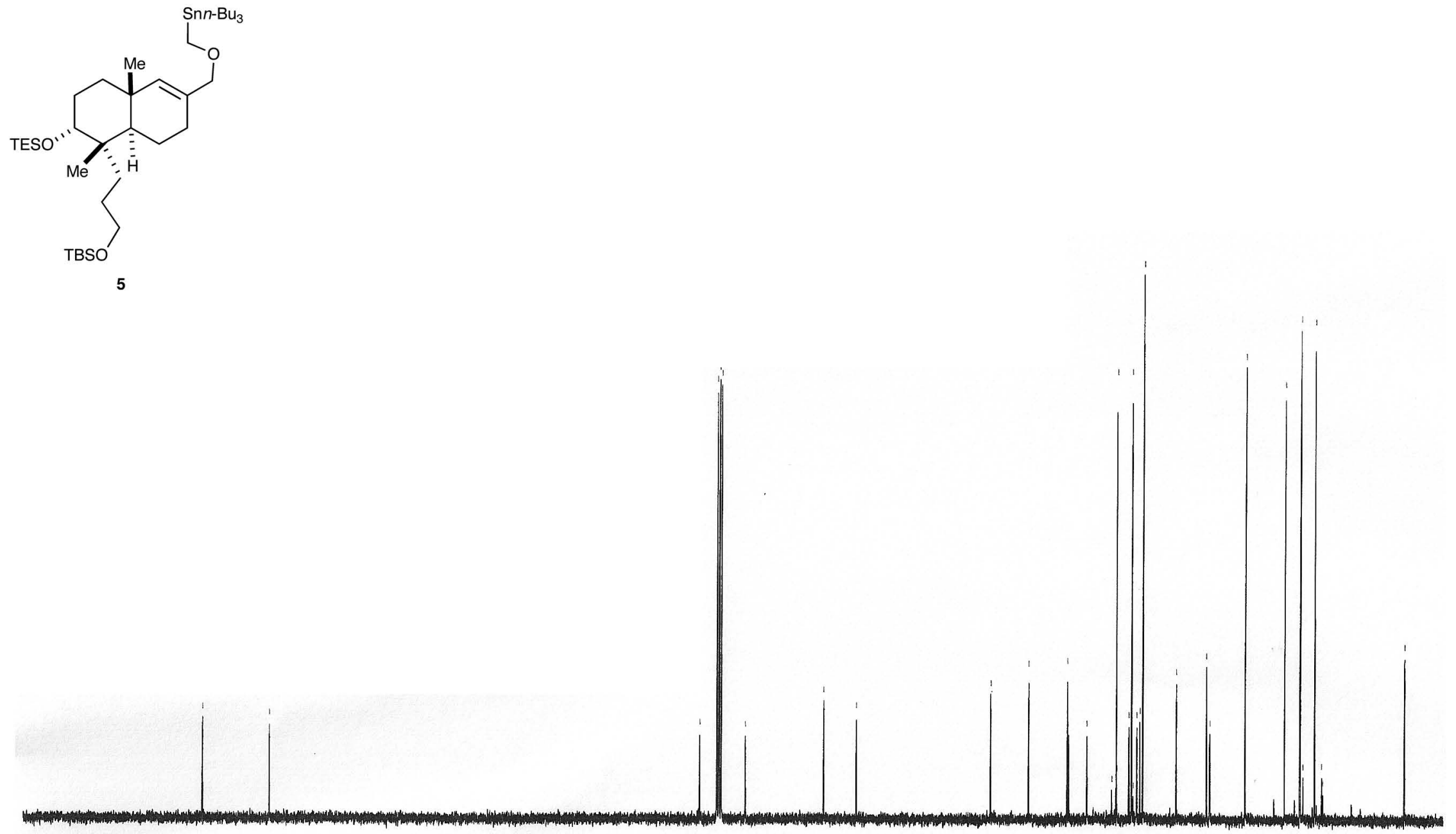




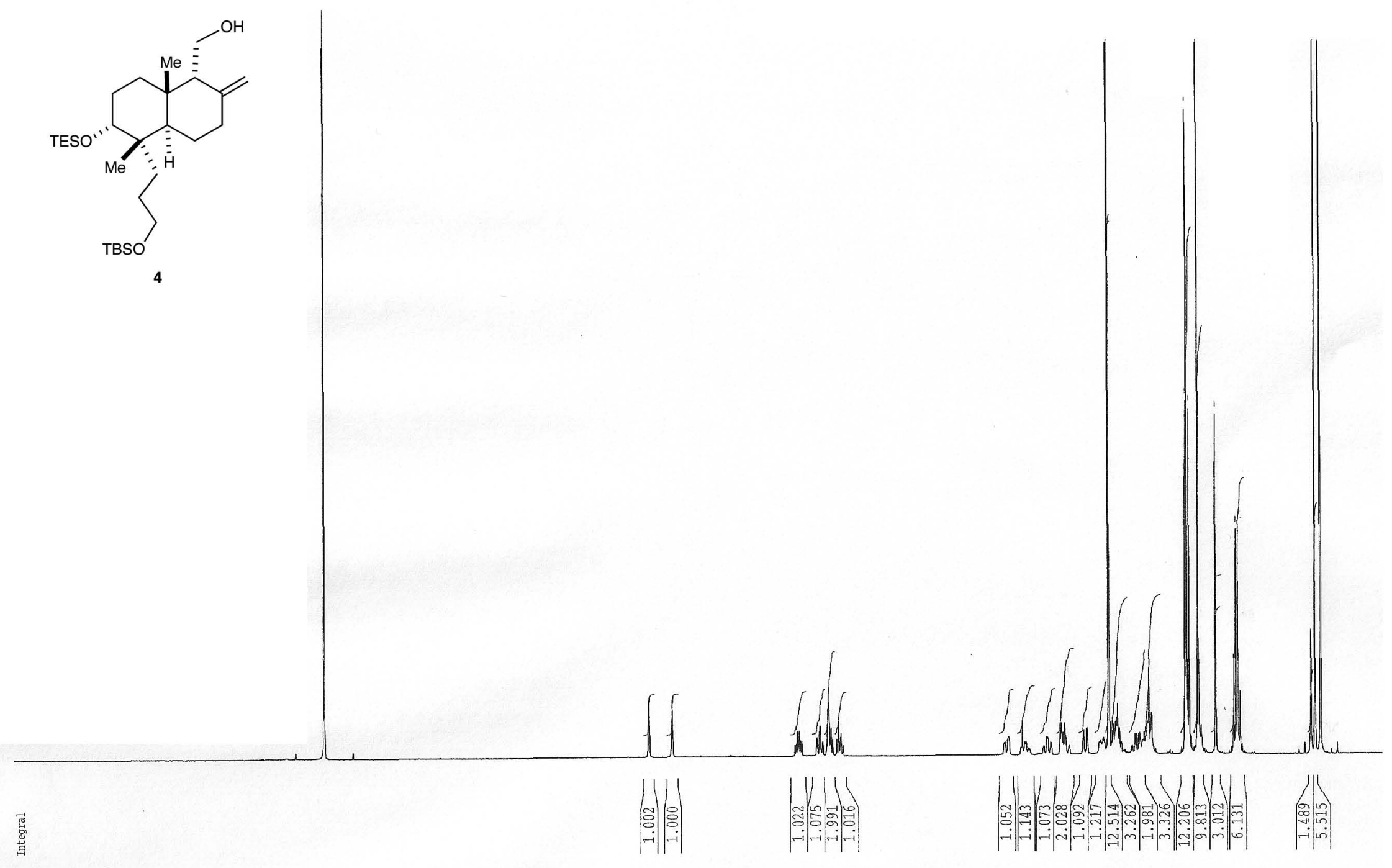



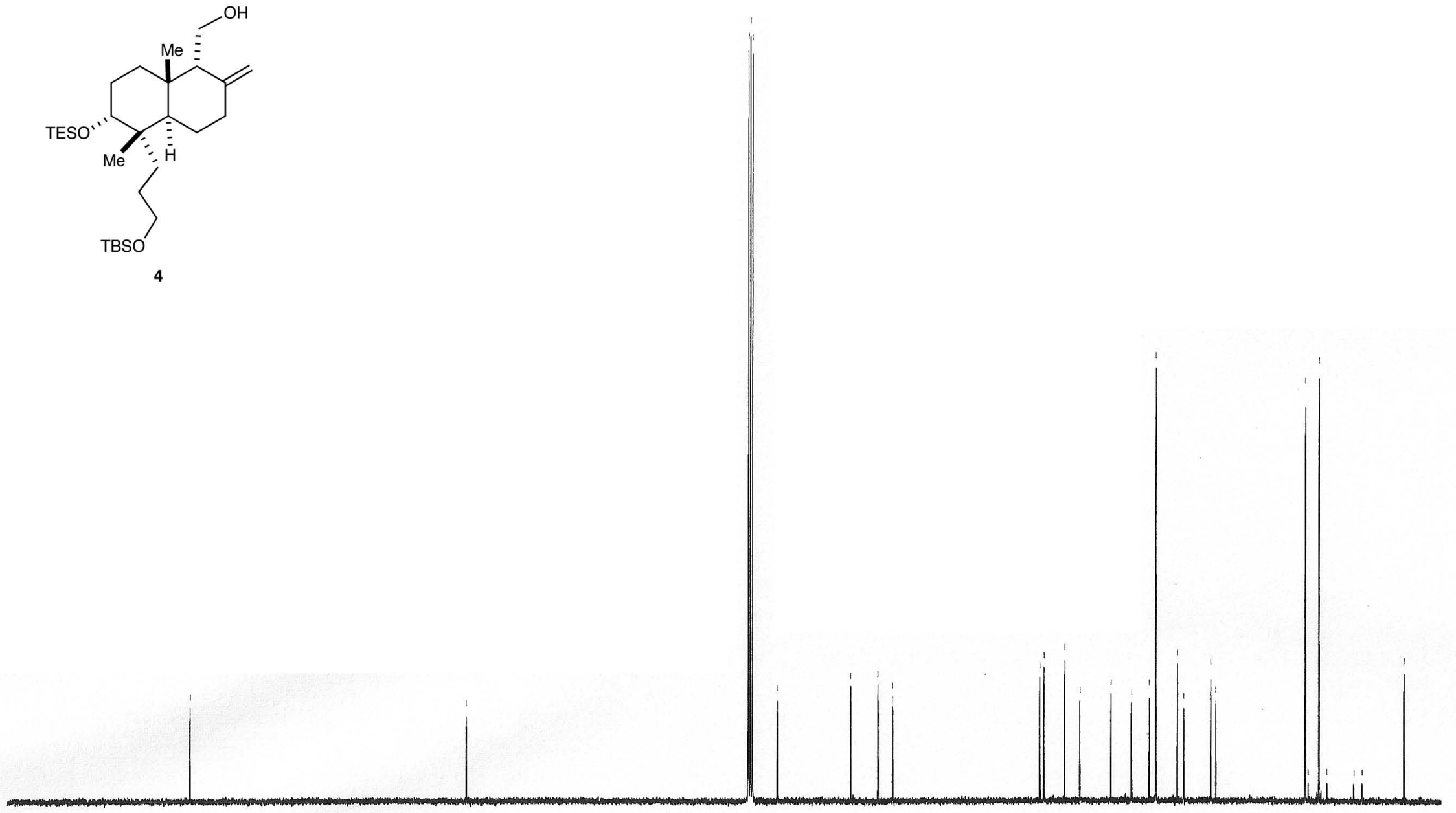

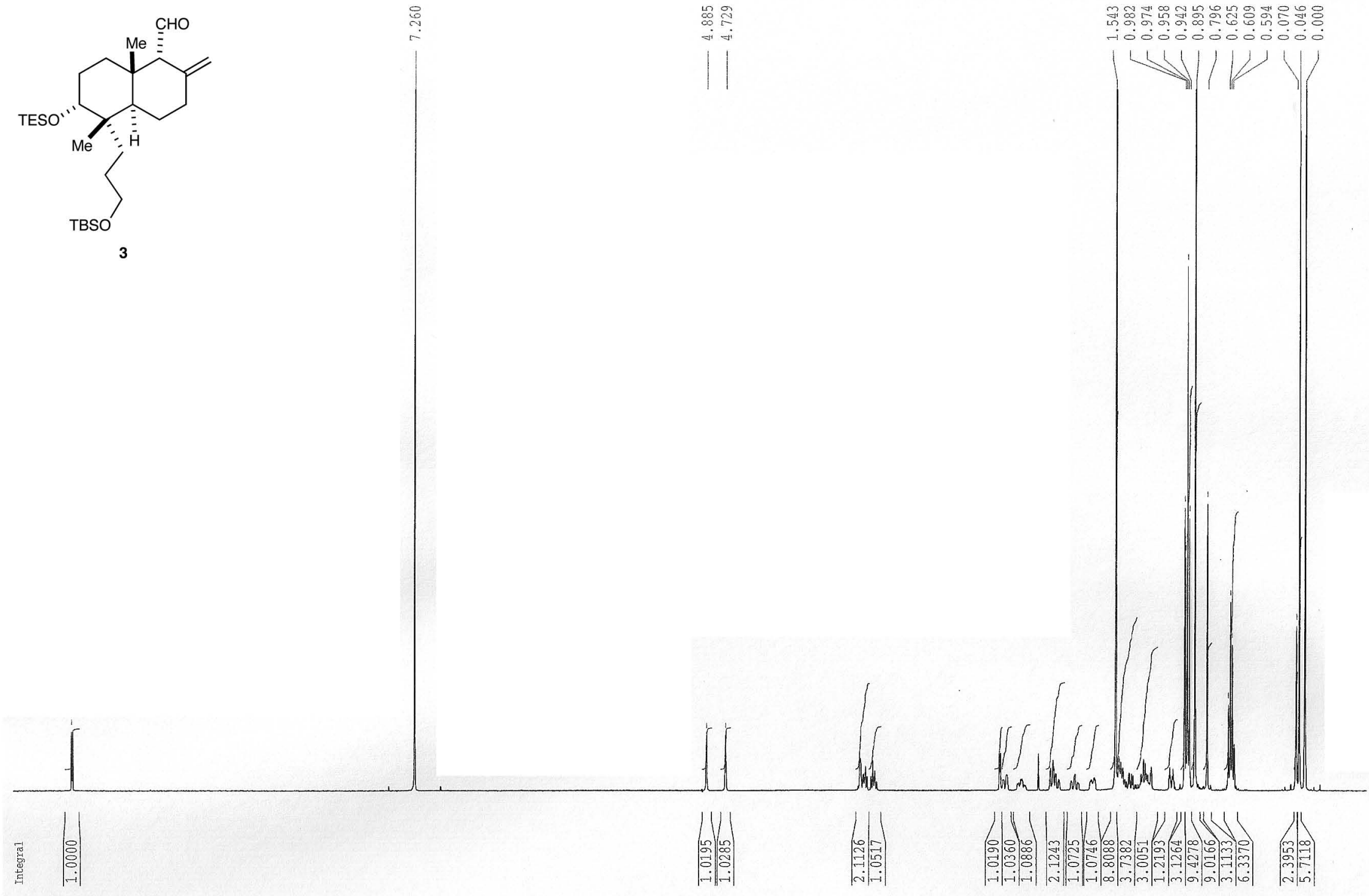

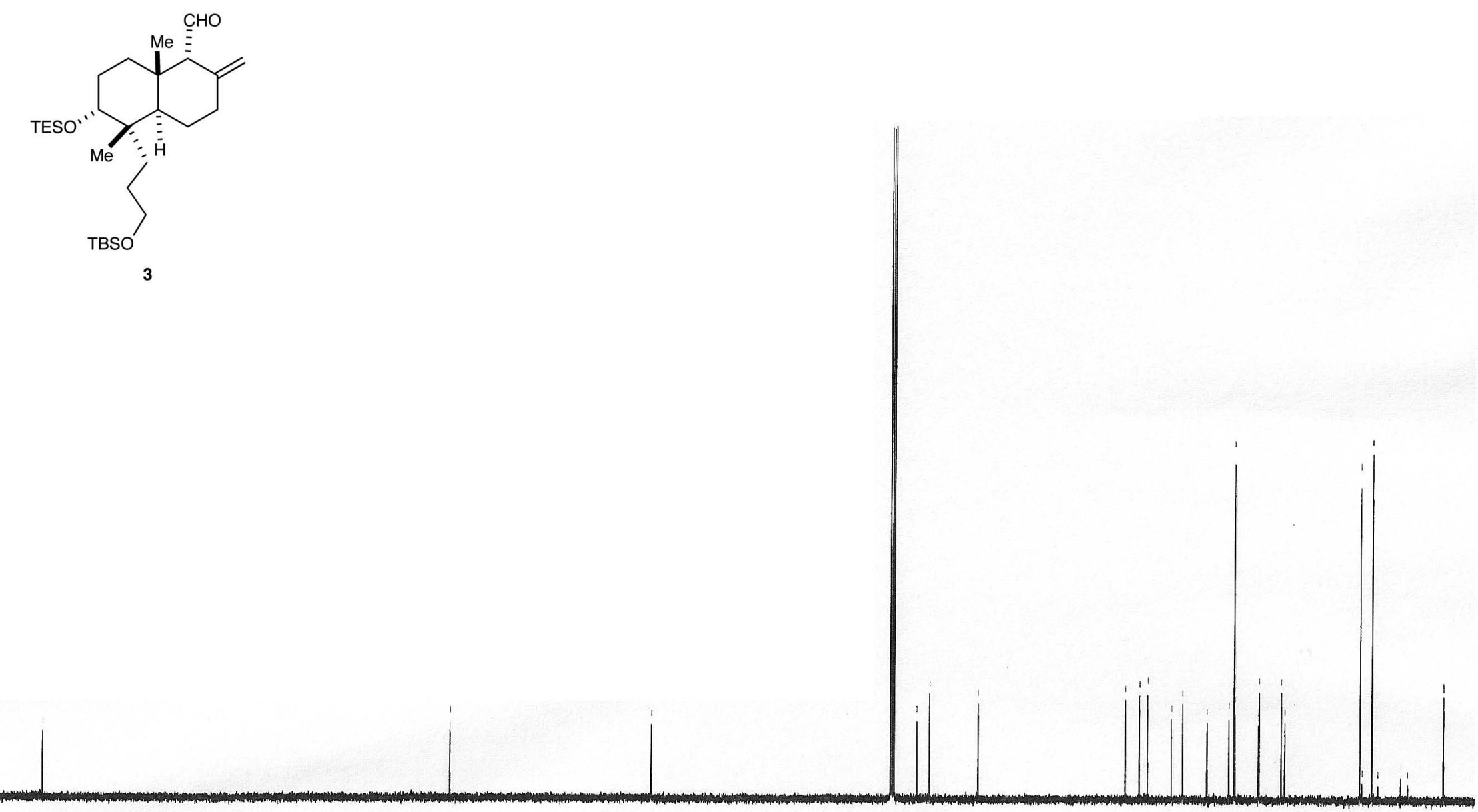


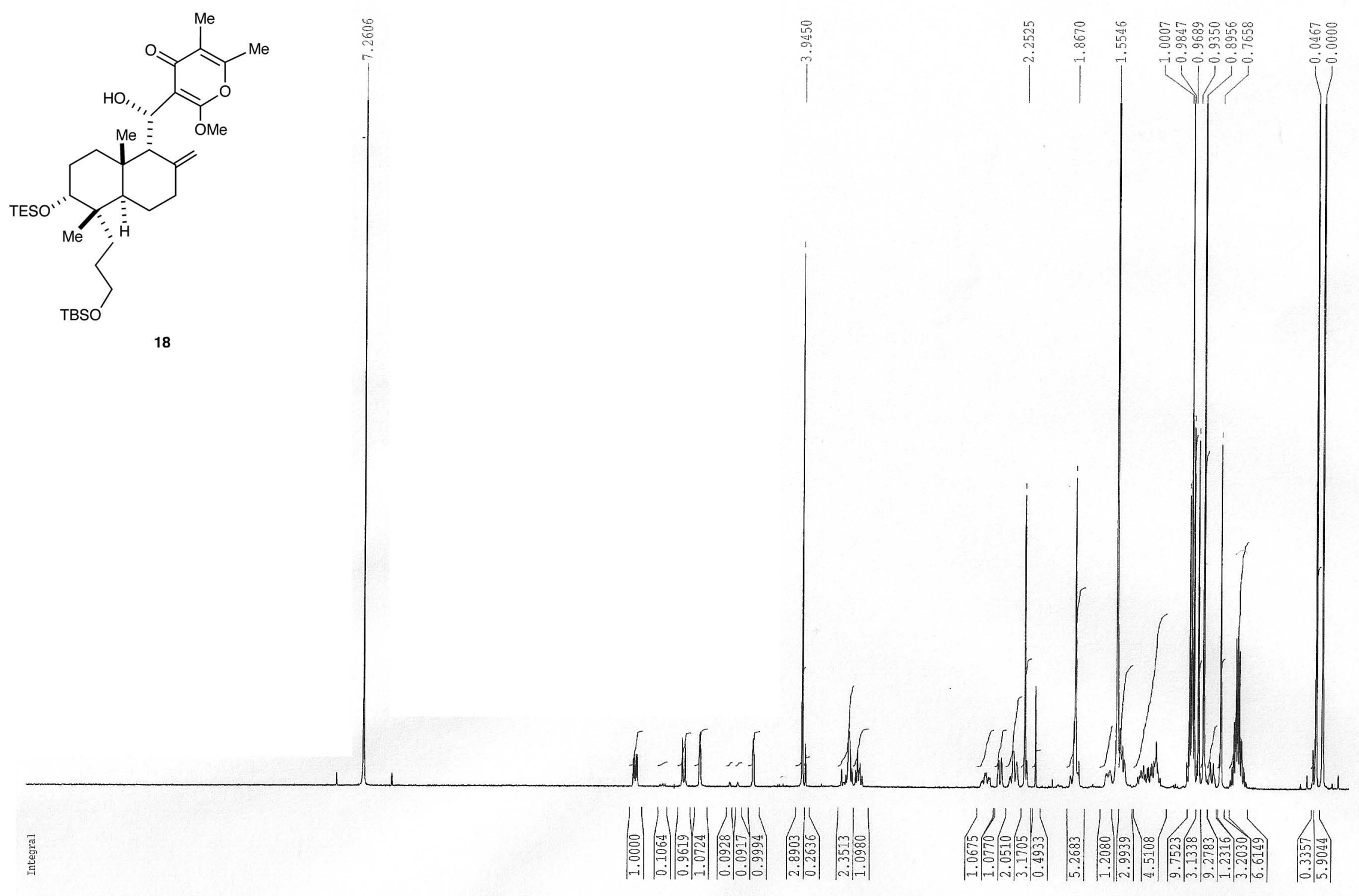




$$
\text { لس }
$$




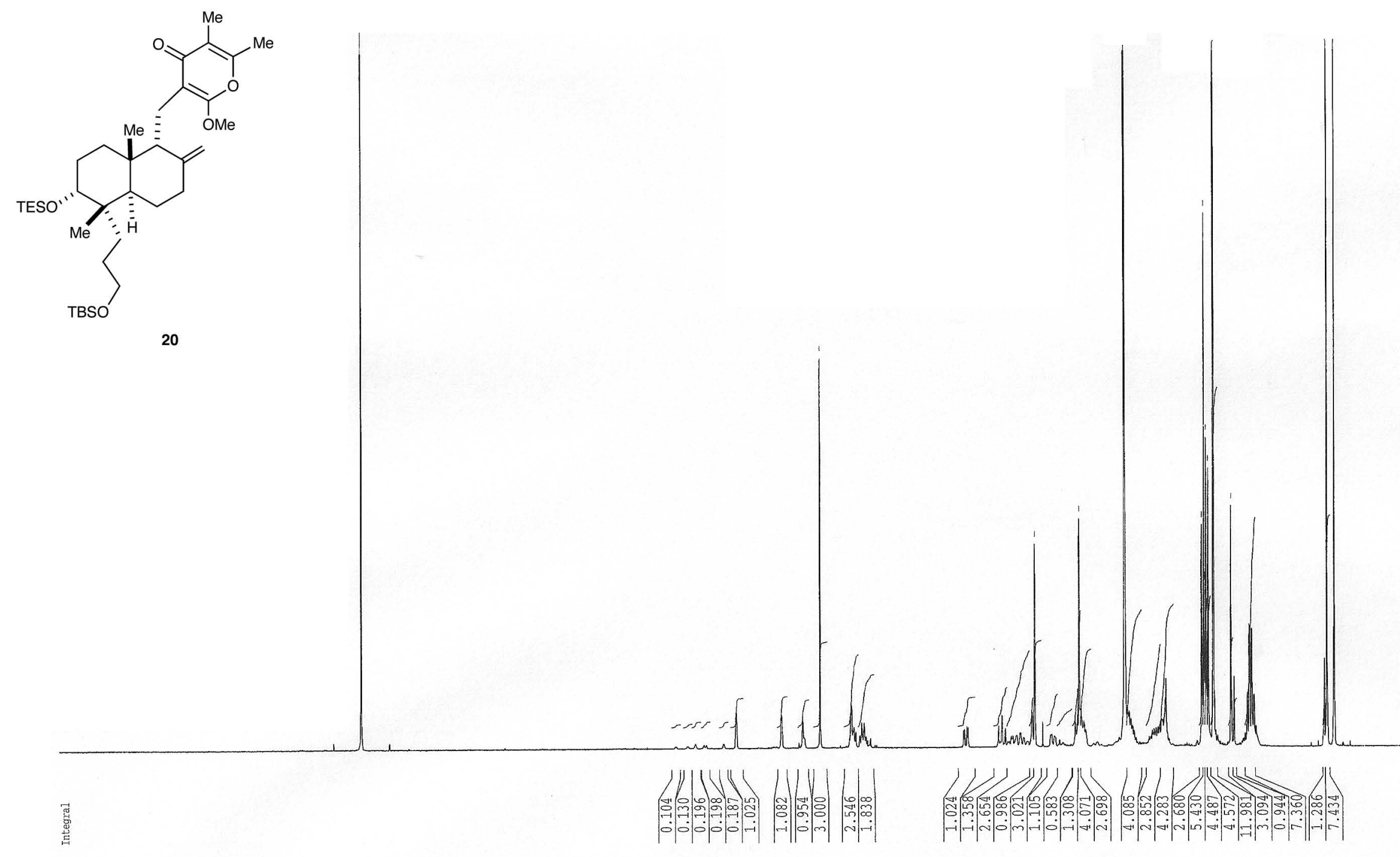




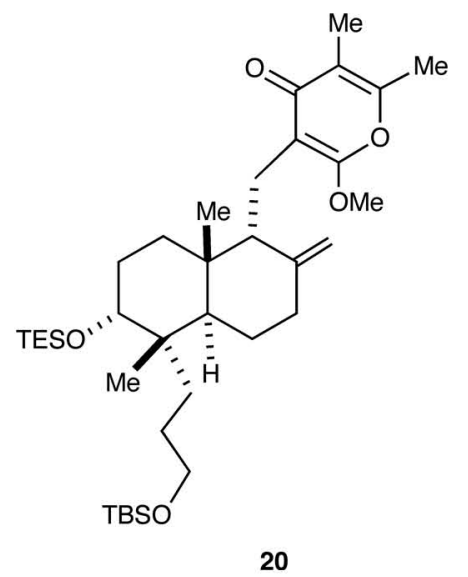




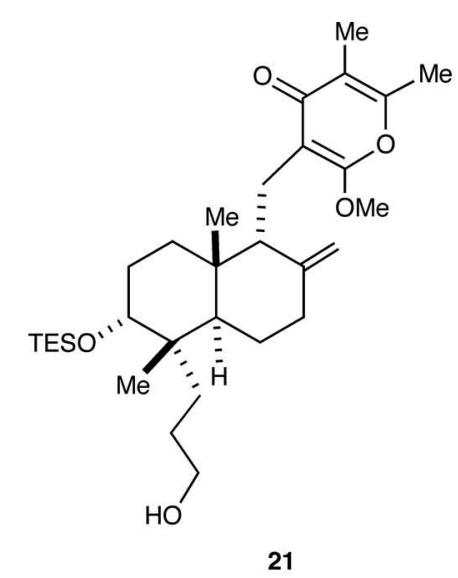




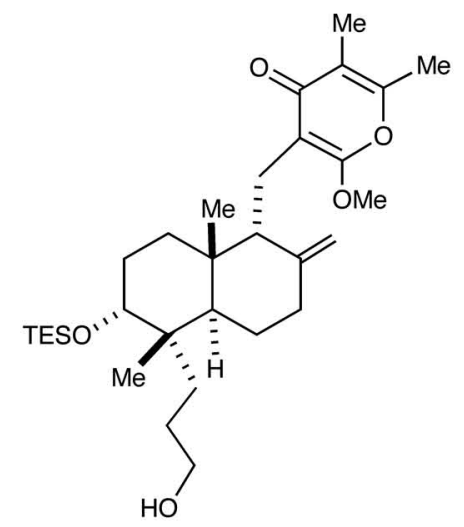

21 


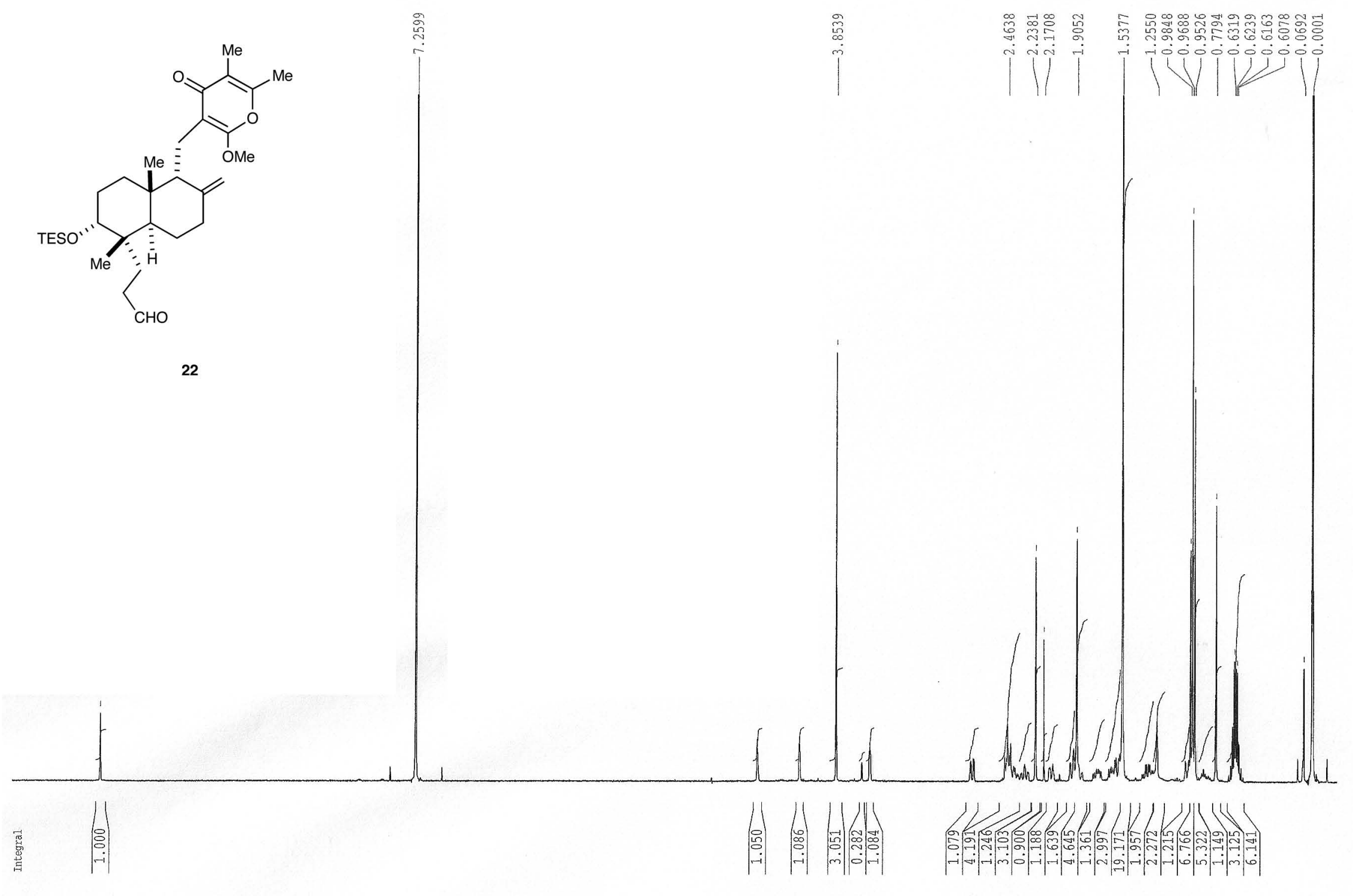




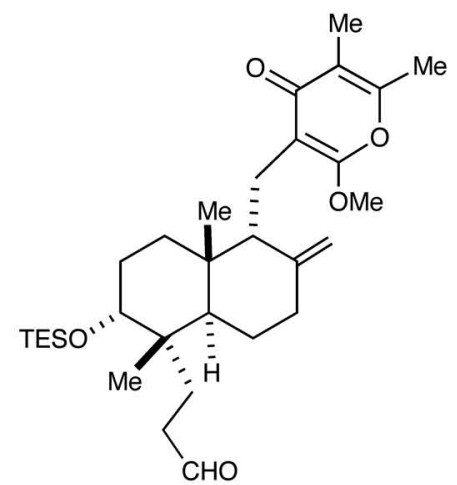

22 

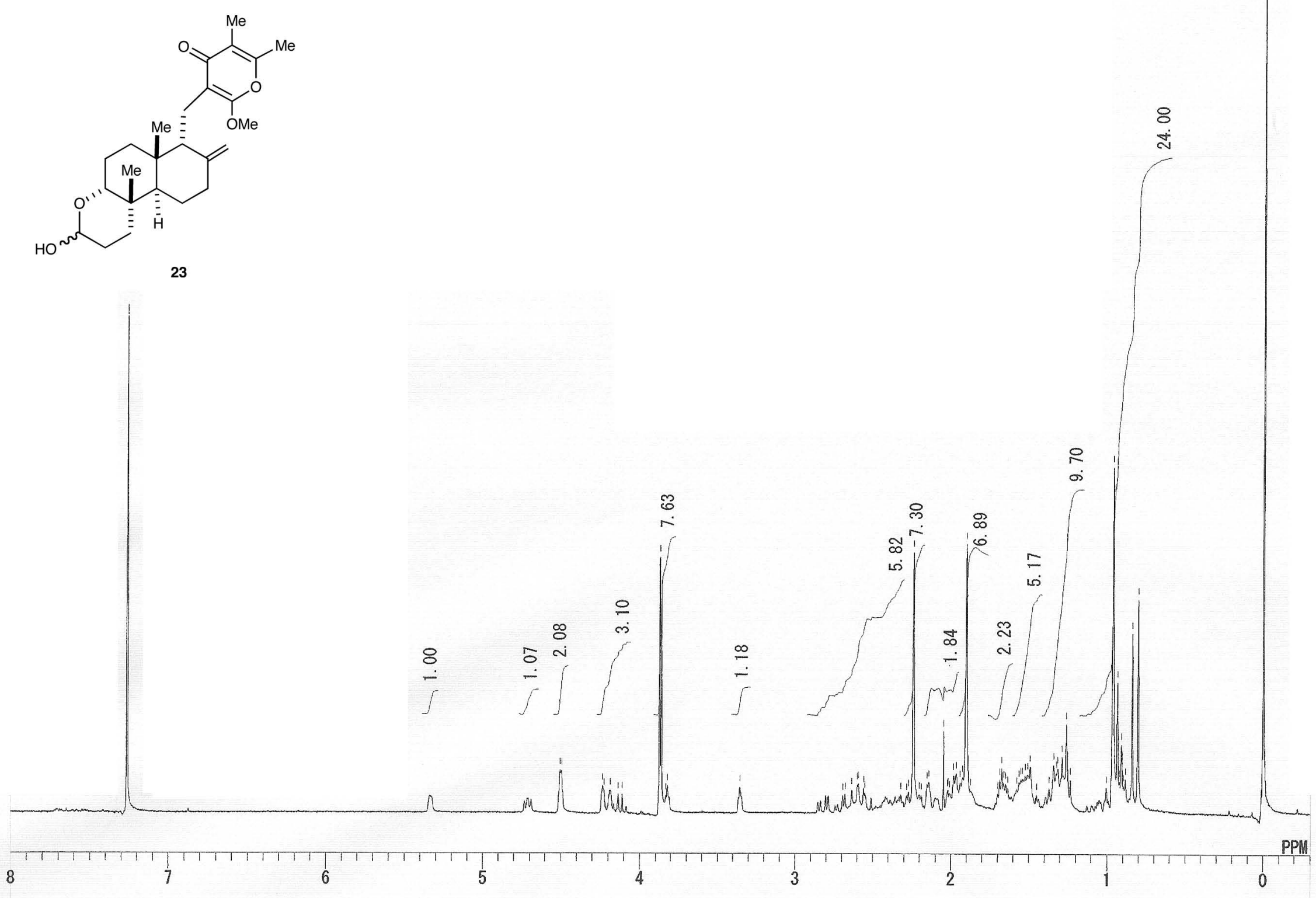

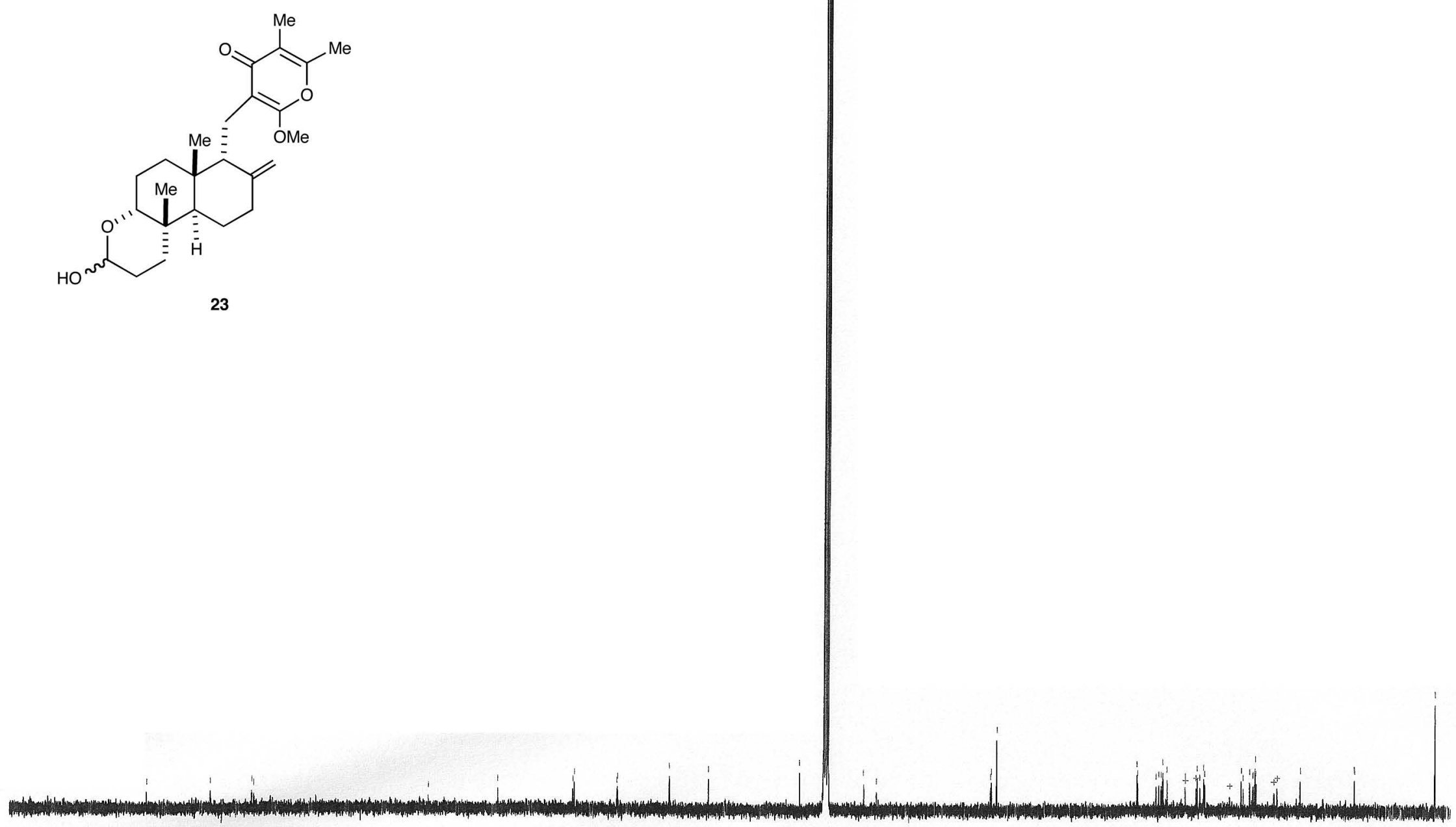


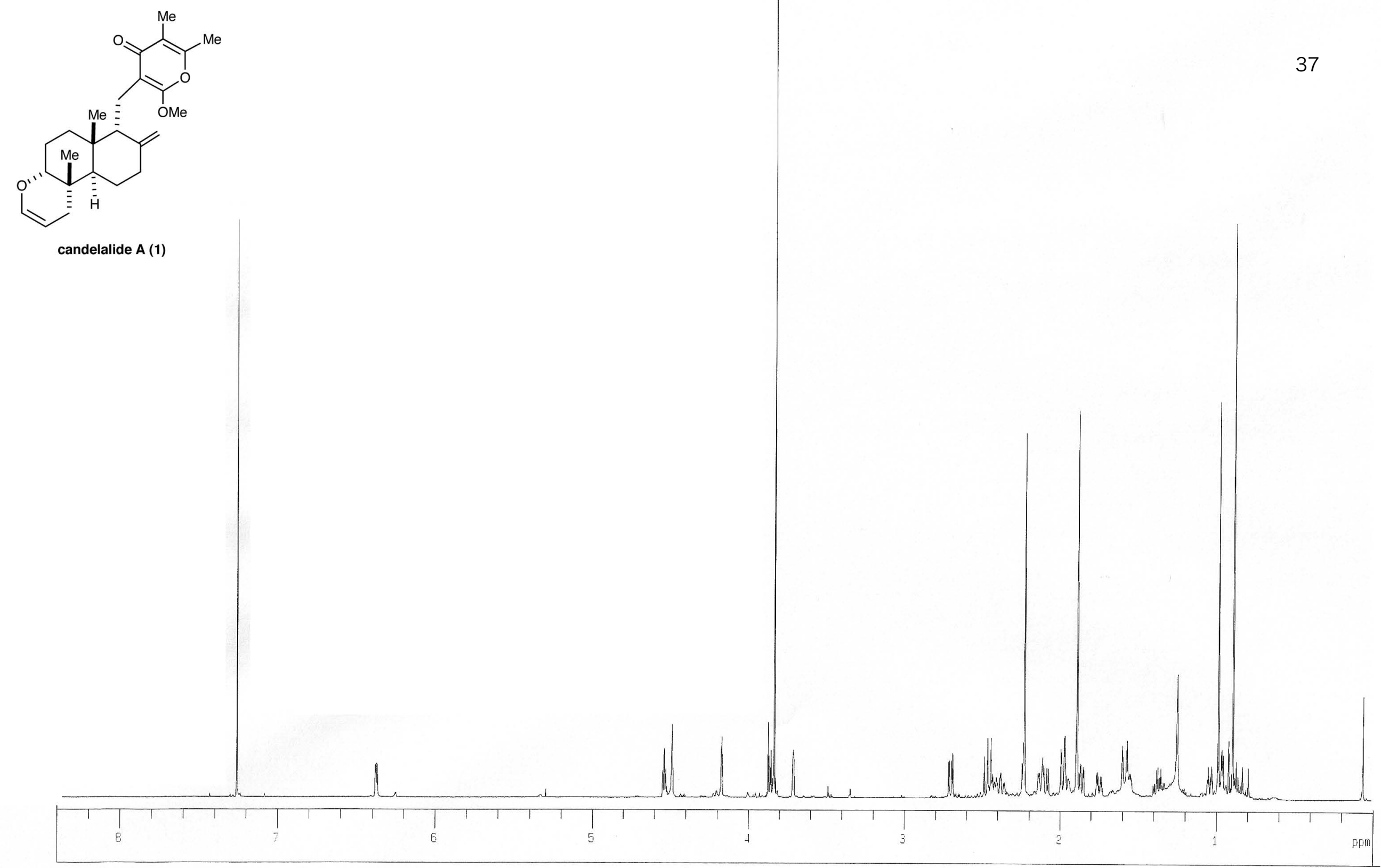




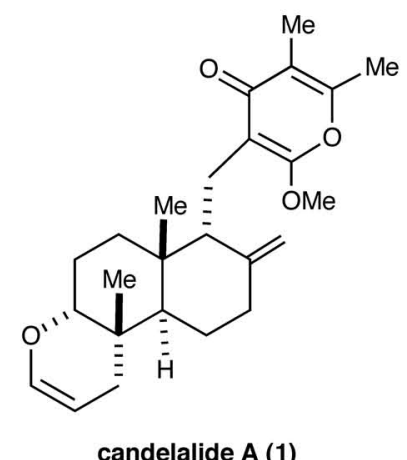

candelalide A (1)

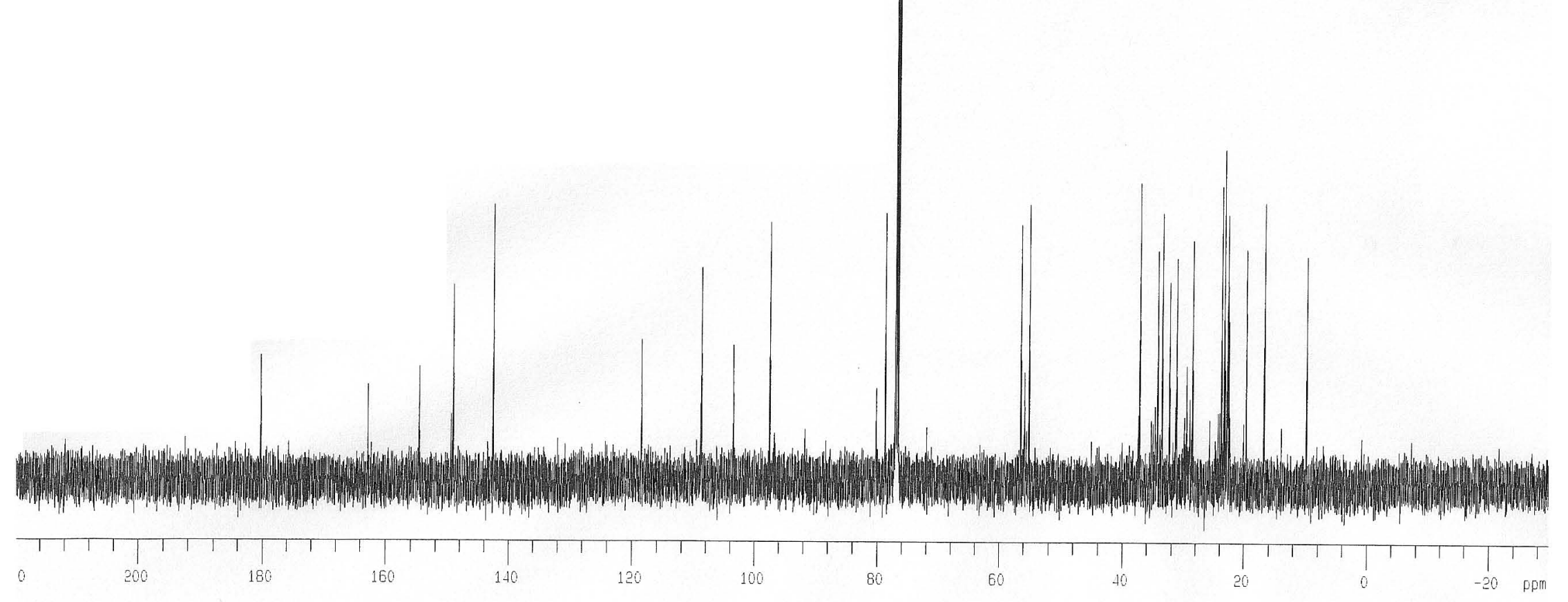

